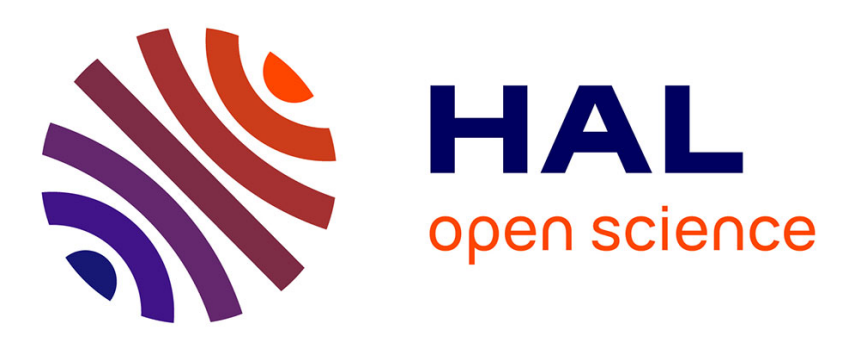

\title{
In situ XANES study of the influence of varying temperature and oxygen fugacity on iron oxidation state and coordination in a phonolitic melt
}

Charles Le Losq, Roberto Moretti, Clive Oppenheimer, François Baudelet, Daniel R. Neuville

\section{To cite this version:}

Charles Le Losq, Roberto Moretti, Clive Oppenheimer, François Baudelet, Daniel R. Neuville. In situ XANES study of the influence of varying temperature and oxygen fugacity on iron oxidation state and coordination in a phonolitic melt. Contributions to Mineralogy and Petrology, 2020, 175 (7), pp.64. 10.1007/s00410-020-01701-4 . hal-02989564

\section{HAL Id: hal-02989564 https://hal.science/hal-02989564}

Submitted on 13 Nov 2020

HAL is a multi-disciplinary open access archive for the deposit and dissemination of scientific research documents, whether they are published or not. The documents may come from teaching and research institutions in France or abroad, or from public or private research centers.
L'archive ouverte pluridisciplinaire HAL, est destinée au dépôt et à la diffusion de documents scientifiques de niveau recherche, publiés ou non, émanant des établissements d'enseignement et de recherche français ou étrangers, des laboratoires publics ou privés. 


\section{Response to Reviewers:}

coordination variations decoupled from redox changes were detected. The data suggest transitions between $\mathrm{Fe} 3+$ in four-fold and six-fold coordination prior to reduction or as a consequence of oxidation. This questions the possible implication of Fe coordination changes in triggering crystallisation of magnetite nanolites upon magma ascent, and, through such crystallisation events, in promoting magma explosivity.

\section{REPLY TO REVIEWERS \\ $X X X X X X X X X X X X X X X X X X X X X X X X X X X X X X X X X X X X X X X X X X X X X X X X X X X X X X X X X$ $X X X X X X X X X X X X X X X X X X X X X X X$}

\#\#\# Editor comments \#\#\#

Editor comment:

I also looked through your paper myself. For me, it was for example not $>$ obvious where in Figure 2 the black data points for different coordination numbers are coming from. This should be directly explained in the figure caption.

\section{Author's reply:}

We understand this comment, and we agree that the presentation of the origin of this diagram was not good, thanks for pointing this. This problem is now solved via the addition of the reference spectra as well as of the reference diagram + reference mineral spectra in Supplementary Figure 2. We also discuss in more details the centroid / intensity diagram in experimental methods, and we clarified the aim of our data protocol and the way we obtained our "updated" diagram.

We hope the changes we made will clear any doubt and solve all the concerns of reviewers 1 and 3 about data reduction. ***

\section{Editor comment:}

Also, I am wondering about the units of the normalized absorbance (normalized to what?) in Figure 1 and of the integrated intensity in Figures 2 to 4.

Author's reply:

Normalised absorbance is the correct notation for the $Y$ axis of XANES spectra that were corrected from any post-edge distortion effect and normalised such that the edge jump is of 1 .

Signal correction and normalisation was performed using the Athena software as indicated in the manuscript, following the recommended procedure.

Integrated intensity directly means the integration of the pre-edge absorbance between the beginning and the end of the pre-edge. Another term would be pre-edge integrated absorbance, but the community tends to always use integrated intensity (see XAS papers of Wilke, Cicconi, Giuli, etc.) such that we respected this. The calculation of the integrated intensity was clarified in the Material and Methods section.

\section{Editor comment:}

Also, as far as I understand, the samples were heated in direct contact with a platinum wire. Normally, one would expect some iron loss due to alloying with the platinum. Did you check for this and can you exclude the possibility that this my have affected your interpretations?

Author's reply:

Yes, they are contained in the Pt wire. As indicated in the experimental methods, we only report results from experiments that were triple-checked for any crystallisation and iron loss. Iron loss to the Pt wire results in a decrease in the measured Fe XANES signal, to modifications in the structure of the glass visible by Raman spectroscopy, 
and of his color. For the reported experiments, the XANES signal was stable, we checked (when possible) after the runs that the Raman spectra of the quenched melt were in good agreement with that of the original material, and we systematically visually inspected, using a microscope, the samples to check that no nuggets of iron were present in the glass.

We observed iron loss to the wire in most experiments with $\mathrm{Ar}-\mathrm{H} 2$, a very reducing gas. We also observed iron precipitation as metal nanonuggets in such experiments. We systematically excluded those experiments.

We need to say that we actually excluded more than half of the experiments we performed because we were not sure about the quality of the signal and that the sample composition was not modified during the run (to the best of our knowledge because microprobe analysis were not possible to perform, see text). No iron loss to the wire or precipitation of iron metal was observed in more oxidising conditions (N2 and Air), in agreement with previous experiments performed with this setup by Magnien, Cochain, Neuville, Cicconi and co.

\section{Editor comment:}

From an editorial point of view, I would ask you to ensure upon revision that the formatting of the manuscript is consistent with this journal. For example, there should be no numbering of headings and subheadings and journal titles in the reference list should be abbreviated.

Author's reply:

Of course, the revised version now matches the formatting of CMP.

\section{$X X X X X X X X X X X X X X X X X X X X X X X X X X X X X X X X X X X X X X X X X X X X X X X X X X X X X X X X X$ $X X X X X X X X X X X X X X X X X X X X X X X$}

\#\#\# Reviewer \#1

Reviewer's comment:

The paper is well written and clearly structured; the abstract contains some language problems that should be looked at. Overall, the results and the analysis are well documented and do constrain most of the interpretations, unless stated otherwise below.

Authors reply:

Sorry about the abstract. We realised it was probably the result of a bad copy-paste of an older version as some sections were not supposed to be like this. We revised the abstract in the new manuscript, and we hope that those revisions solve this problem.

Reviewer's comment:

As outlined below, the cited literature is strongly biased and should be adopted to represent the work that has been done in that field.

Authors reply:

Excuse us about such bias, we tried solving this in the revised version, paying more attention to the references and citing more various sources of references from the works of Giuli, Wilke, O'Neill, Berry, Cicconi, Fiege, Cottrell, Zhang... We believe this solves the problem.

Reviewer's comment:

The authors use the pre-edge centroid as a figure of merit to trace the changes in oxidation state, without converting to actual values of $\mathrm{Fe} 3+/$ Fetot. This is fully 
acceptable to analyze the dynamics of the reaction. Still they do plot pre-edge intensity and centroid on the diagram of Wilke 2001 and start interpreting the intensity in terms of site symmetry in an quantitative manner. The authors have not shown at all that their data reduction is consistent with the values of that diagram. This needs to be checked by known samples, e.g. known glasses or model compounds.

\section{Authors reply:}

We understand the concern of the reviewer. Indeed, we originally have not shown the reference diagram implemented in our laboratory with our data reduction protocol. We cited the thesis of Cochain, but we understand this is not enough.

As a consequence, we added the spectra of the reference compounds as well as the reference diagram in Supplementary Figure 2. The data reduction protocol is better presented in the Material and Methods section, as well as the establishment of this reference diagram with the used data reduction protocol.

We hope those changes will fulfil the reviewer expectations, and solve this problem. Thanks for pointing this weakness!

\section{Reviewer's comment:}

Given the quality of the data presented in Fig. $1 \mathrm{~b}$, I suspect that the very low pre-edge intensity observed for samples in N2-gas is an artifact of the treatment. In fact the preedge intensity in figure $1 \mathrm{~b}$ is quite low, which looks weird. Other in-situ measurements have not shown this (Wilke et al. 2007, Magnien et al. 2004, 2008). Especially, extracted pre-edges in the first two look pretty similar and different to those here.

\section{Authors reply:}

It is normal that our integrated intensities do not match those of Wilke or Magnien, as our data reduction protocol is not the same. Again, we take that into account by implementing a revised version of the centroid vs II diagram that was made using our protocol.

The pre-edge intensity in Figure $1 \mathrm{~b}$ for the $\mathrm{N} 2$ sample just reflect the fact that this spectrum contains a mixture of $\mathrm{Fe} 3+/ \mathrm{Fe} 2+$. Actually, the two contributions are fairly visible, and the intensity is coherent with what it should be. Also, the Ar- $\mathrm{H} 2$ spectrum is more noisy due to Ar absorbing a significant portion of the X-rays at $\sim 7114 \mathrm{eV}$.

\section{Reviewer's comment:}

The authors need to prove that their data treatment is consistent with plotting it on this diagram. Otherwise, just don't use it and cut out all considerations regarding the site symmetry (coordination) of Fe. Analysis of the dynamics and extraction of the transport parameters should not be affected by this, as it directly uses the centroid.

\section{Authors reply:}

We believe that this problem is now solve with the addition of all the details mentioned above.

\section{Reviewer's comment:}

Line $43 \mathrm{ff}$.: The overview on the literature does not give a comprehensive picture on the work that has been done on Fe in melt. Furthermore, it is strongly biased on work of the group, i.e. Neuville and friends. Wilke et al. 2001 is the basis for this XANES work, but the paper on quenched glass is Wilke et al. 2004. Anyway, there is further work to be cited in the XANES business! The sentence line $49-50$ is even wrong by content. That $\mathrm{Fe} 3+/ \mathrm{Fe} 2+$ partitioning is driven by the mentioned parameters is known way longer than those papers cited at this position. Please, correct this and provide a fair overview on the current status of the literature Fe in melts as well as the XANES approach. 
Authors reply:

We believe the new version should avoid such citation caveat, and corrected this sentence. See the new introduction, lines 71-86.

Reviewer's comment:

Line 60: Again literature is not complete. The in situ study of Wilke et al. 2007 (AmMin 92, pages 44-56) is missing, as well as the one of Drewitt et al. 2013 Phys Rev B 87, 224201 (2013). There is even a short paper that describes a very similar experiment as the one here (Wilke et al. 2007, AIP Conf. Proc., 882, 293-295). Those data a very consistent to these presented here.

Authors reply: Thanks, we added those papers.

Reviewer's comment:

Line 67: What is meant by Fe3+/Fetot data are available for this composition and what is meant by parametrization? Please, specify in more detail. If this is so well known, why don't we find any comparison in the text? It would be really helpful to see what oxidation state can be expected for the used conditions.

Authors reply: This sentence was actually clumsy and thus removed from the new version. The reviewer will also appreciate that the comparison is now provided in Figure 5.

Reviewer's comment:

Line 102: The units of the oxygen fugacity are missing. Bars? Only log fO2 has no units. Please, correct!

Authors reply: Corrected!

Reviewer's comment:

Line 119: How can the composition of a glass be determined by Raman spectroscopy? This is non-sense, for the composition you would need to use microprobe or a SEM with EDX. In any case, provide a correct statement. Specify whether you really looked at the composition after the experiment by an appropriate method. If not then discuss the potential errors on the composition.

Authors reply:

It is very difficult to embed a full platinum wire in an epoxy ring for EMPA measurements. Plus we don't want to do that because Pt wires are expensive, have a time-consuming T-I calibration, and thus they are meant to be cleaned in HF and reused for performing other experiments. So we had to check that sample composition was not affected during the experiments by other means.

There was little details on this part in the previous manuscript. In the revised version, we added more details on the protocol we adopted to prevent compositional changes or iron precipitation/alloying, and on the steps we took to detect such changes.

Instead of going in details there, we invite the reviewer to have a look at the new Material and Methods section, lines 197-233. All elements are present to reply to this comment.

Just a precision: appropriately calibrated, Raman spectra can be used to determine the composition of a glass to within 0.5 to $1 \mathrm{~mol} \%$, depending on the element (see Di Genova et al. 2015 Journal of Raman Spectroscopy 46: 1235-1244 for an attempt on experimental glasses, and more particularly for a real application on MORB glasses Le Losq et al. 2019 American Mineralogist 104:1032-1049). Indeed, Raman spectroscopy is very sensitive to changes in the glass structure, which is driven by glass 
composition. This is why, with some experiences performed at conditions similar to that of the original glass synthesis, we can check that Raman spectra of starting materials and of the glass from the experiments match. No differences indicates no change of glass composition in a quite tight chemical domain.

Reviewer's comment:

At reducing conditions Fe may be easily lost to the Pt-wire, as documented by many studies.

Authors reply:

Yes, we had trouble for a fair number of experiments that showed significant changes in Raman spectra as well as optical changes as checked with the microscope. Those experiments were discarded, and are not reported in this publication as indicated in the Materials and Methods section.

To be honest, most experiments in Ar-H2 were affected by this effect and are not reported. Experiments in Air or N2 were not affected by this phenomenon, explaining why reported dynamic runs were made under those fO2 conditions.

$\mathrm{Ar}-\mathrm{H} 2$ runs were not informative as, except at the beginning of the experiment were a few spectra can be acquired (the spectrum in Fig. 1B was acquired after 10 minutes of equilibration at the beginning of a run for instance), iron precipitated in most cases. This is why no dynamic runs under the Ar-H2 atmosphere are reported.

We must say that on 7 successfully performed "dynamic" runs, only three were really good as they met strict criteria indicating no crystallisation, no iron loss, no chemical change in the sample. In the other runs, we sometime tried to introduce $\mathrm{Ar}-\mathrm{H} 2$ that resulted in Fe loss, we also set temperature at values too low resulting in a crystallisation visible on the XANES spectra and optically after the experiments, or simply the run went fine but the post-experiment Raman spectra looked odd (see Supplementary Materials for examples).

Again, we tried to better report on this in the Material and Methods section, so we invite the reviewer to have another read. We hope the new version will give a better overview of the performed work, and of the measures we took to be sure that sample chemical composition changes are negligible.

Reviewer's comment:

Line 135: Using the diagram of Wilke et al. 2001,2004 means that the authors have to prove that their data treatment is consistent with the one used to construct the diagram. This could be easily done with a few measurements on glasses with known oxidation state.

Authors reply:

We were not be very clear in the previous version of the manuscript, but the data treatment for constructing the centroid versus intensity diagram is the same as the one used for the glasses. Indeed, the Wilke diagram had to be adapted to the results obtained with our data reduction protocol. To clarify this, the new version of the manuscript presents in Supplementary Figure 2 the reference materials used for reconstructing the centroid versus intensity diagram, and this is now much better presented in the new manuscript (see Lines 235-270).

Reviewer's comment:

Figure 1: The quality of the data measured in air seems great. However, those in Fig. $1 \mathrm{~b}$ are much worse. I am completely disturbed by the low pre-edge intensity of the N2spectrum. With such data it seems questionable that the analysed centroid and intensity values can be directly compared to the centroid diagram without further proof.

Authors reply: 
The pre-edge intensity of the N2 spectrum is not low, it is actually bimodal with a clear separation between $\mathrm{Fe} 2+$ and $\mathrm{Fe} 3+$ contributions. We want to remind the reviewer that $\mathrm{Fe} 2+$ contribution is much less intense that the Fe3+ contribution (see intensity versus centroid diagrams).

The integrated intensity of this signal agrees with the trend [5]Fe2+ - [5]Fe3+ reported in figure 2 for instance.

The higher noise under the $\mathrm{Ar}-\mathrm{H} 2$ atmosphere is due to the higher absorption of $\mathrm{X}$ Rays by Ar than by air, O2 or N2.

\section{Reviewer's comment:}

I am not questioning that the values do reflect the state and dynamics of the oxidation state. I only question that you can compare them to the diagram. Since the systematics of the oxidation state in this melt system are known (see above), the authors could provide info what the expected oxidation state is for the given conditions. This way one could document how the centroid position on the diagram reflects the oxidation state.

\section{Authors reply:}

Thanks for this comment. We originally thought this would not bring something to the discussion, but you made us realize that this will be better with the comparison!

This is now performed, see Results section lines 325 - 356 and new Figure 5.

\section{Reviewer's comment:}

Line 195: I have never seen such a trend on the centroid diagram. Data of the in-situ study of Wilke et al. 2007 plot very similar to the trend known for glasses from many other XANES studies. This is a further indicator that the authors should first proof that their data treatment is consistent with this diagram. What are the expected oxidation state values for the presented conditions? E.g. by Schuessler et al. 2008, Kilinc et al. or the Moretti model?

\section{Authors reply:}

Please again see new Figure 5 for the oxidation state of iron.

Yes, we also never saw such a trend. But to our knowledge, nobody really reported trends in this diagram during dynamic in situ experiments... The dynamic Wilke experiments do not report data in the centroid versus integrated intensity diagram as they only acquired a very limited portion of the signal (actually at one given energy). Therefore, the lack of systematic records of in situ XAS spectra during iron redox changes in melts may explain why this has never really be reported previously.

There is no problem with the oxidation state of the melts, see Figure 5 where equilibrium data from all experiments presented in Figures 1 to 4 are reported.

Thus, with changes in redox coherent with expectation, we have changes in $\mathrm{Fe} \mathrm{CN}$ that are happening during the dynamic experiments. At the moment, we have no real answer about the factor controlling such changes. This will be the topic of new experiments in the upcoming years.

\section{Reviewer's comment:}

Line 222: This is a completely unconstrained statement. How can the authors detect ionic couplings with surrounding oxygens by XANES?

Authors reply: Wrong choice of word, this was deleted.

Reviewer's comment: 
The pre-edge reflects the average site symmetry, nothing more.

Authors reply:

Yes, we just meant that by detecting $\mathrm{Fe} 3$ in $\mathrm{CN}$ 4-5 via XAS and coupling this information with the theory, this implies $\mathrm{Fe} 3+$ as a network former unit in $\mathrm{FeO} 4$ and FeO5 polyhedra. But again, wrong choice of word, and the discussion of the new version changed significantly for improved clarity. We invite the reviewer to have another look at the discussion.

Reviewer's comment:

If well calibrated the authors may turn this into information on the average coordination polyhedron. I am missing the calibration!

Authors reply:

Again, we understood this point and as commented several time above, we provide such data now. Please see Material and Methods, Supplementary Figure 2 and the new Results section.

Reviewer's comment:

Line 345: It has been shown that the Fe oxidation state may be easily changed at temperatures just above the glass transition (e.g. $600^{\circ} \mathrm{C}$ ), Burkhard 2001, J Petrology $42,507-527$. So, this final statement seems to be rather arbitrary. Further, the whole paragraph does not mention at what temperature the scenario is discussed. Please, rewrite.

Authors reply:

The lava lake size is of $40 * 80$ meters, with a depth that probably scales in the $\sim$ tens of meter value. Typical residence time of the magma is of the order of $\sim 5-10$ minutes (see reference in the manuscript), so even with diffusion at $\mathrm{Tg}$ (much slower than at $1100{ }^{\circ} \mathrm{C}$ !) you would have only a very limited diffusion front and would not modify the bulk redox state of the magma.

This is actually what is happening because the redox state of the magma is more reduced at surface that in the deep part of the conduit. Please see Oppenheimer et al. (2009) for details and Discussion in this paper.

We modified the paragraph to include the temperatures (they were in Figure 6). This statement is not arbitrary but results from a logical deduction, so we did not modify it.

Reviewer's comment:

Line 354: I think the statement on the structural role is completely unconstrained, which is based on the defined reactions used for thermodynamical analysis. Even a 4-fold coordinated $\mathrm{Fe} 2+$ cannot be regarded as network-modifier due the low field-strength of this cation.

Authors reply:

We guess the reviewer meant that $\mathrm{Fe} 2+$ in four fould coordination cannot be regarded as a network former, and we agree. We modified the manuscript and our equations to take that into account.

Reviewer's comment:

One could rather consider it as a strong network modifier.

Authors reply: Yes, we agree. 
Reviewer's comment:

If there is really 4-fold coordinated $\mathrm{Fe} 2+$ then this rather indicates the shortcoming of our simple picture of silicate melts. Mg2+ shows a very similar structural role as Fe2+, no one would ever consider it as network former.

Authors reply:

This is a valid point, indeed. We did not really consider Fe2+ in CN4 as a network former unit in the same way as Si for instance, but rather wanted to point that $\mathrm{Fe} 2+$ in CN4 may have properties very different from other CNs... In any case, it is unlikely to find $\mathrm{Fe} 2+$ in $\mathrm{CN} 4$ given our data. We thus rewrote this part to clarify things.

Reviewer's comment:

Please, rewrite all these assignments in an appropriate way, so that it is constrained by the data. I do admit though that Fe3+ may be found in both structural roles, similar to $\mathrm{Al} 3+$.

Authors reply: Done, please see the new version od the discussion, and in particular lines 388-410.

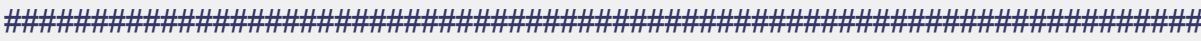
\#\#\#\#\#\#\#\#\#\#

\#\#\# Reviewer \#2

Reviewer's comment:

Line 18: Missing 'of' before iron.

Authors reply: Corrected.

Reviewer's comment:

Line 30: I would suggest to change 'hence on how they associate' to 'associating' (and 'releasing') to simplify the sentence.

Authors reply: The abstract has changed, we hope the new version will fulfil the reviewer's expectations.

Reviewer's comment:

Line 47: Can the authors give one or two examples of how iron oxidation state affect the physico-chemical properties of melts?

Authors reply: Examples are now provided, please see the new introduction.

Reviewer's comment:

Lines 59-60 and 65-66: Simplify/Reorganize by saying 'can however be studied in-situ (i.e, at high temperature in the liquid state) using [...XANES] spectroscopy' and 'In this study, we used in-situ Fe K-edge XANES spectroscopy to investigate the coordination'.

Authors reply: Done, thanks.

Reviewer's comment:

Line 70: Signal without s?

Authors reply: Corrected.

Reviewer's comment: 
Line 80-81: can the authors briefly mention what kind of method they used to prepare the crystal free starting material? It's only few extra words, but it helps the reader not to have to go and check in previous papers... The reference to Le Losq et al. should however be kept.

Authors reply: Yes, good point. We added a whole paragraph and kept the reference for details.

Reviewer's comment:

Line 89: I would suggest using 'in-situ XANES measurements' rather than 'experiments by XANES spectroscopy'.

Authors reply: Done.

Reviewer's comment:

Line 98: specify 'intensity on the Pt wire'.

Authors reply: Done.

Reviewer's comment:

Line 99: 'and temperature was monitored during measurements with an optical pyrometer' - I think this formulation would be clearer for non experimentalist?

Authors reply: Yes, corrected.

Reviewer's comment:

Line 125: The authors had just finished describing Raman spectra, so I would advise to say XANES spectra here, so that the sentence is clearer for the reader.

Authors reply: Yes, thanks, corrected.

Reviewer's comment:

Line 138: 'the Fe K-edge edge' - to correct.

I would also advise to replace 'constant fO2' by 'air fO2'. Or even just mention 'in air (fO2=0.21).

Authors reply: Corrected

Reviewer's comment:

Line 144: 'varying fO2 (air, N2, ArH2)'

Authors reply: Corrected.

Reviewer's comment:

Line 144-147: I suggest to change to 'clearly showing the reduction of $\mathrm{Fe}$, until $\mathrm{Fe} 2+$ dominates under $\mathrm{ArH} 2 \mathrm{fO} 2$ (10-15)' to shorten the sentences.

Authors reply: Thanks, modified.

Reviewer's comment:

Line 195: the Authors mention Fe3+ in CN4. Is that for air (ie., not shown in Figure 2 or 3)? Please explain.

Authors reply: We deleted this sentence, it was not right and not very informative. This helped improve this part. 
Reviewer's comment:

Lines 215-217: Why using the prime notation and not FellFellI?

Indeed, the Fell FellI notation will be more coherent with e.g. Moretti 2005 for instance.

Authors reply: Yes, thanks, this is a good point, and we modified the text to follow the notation introduced in Moretti (2005)

Reviewer's comment:

Line 222-223: remove nevertheless

Authors reply: Corrected.

Reviewer's comment:

Line 227: Missing space between these and phonolites

Authors reply: Corrected.

Reviewer's comment:

Line 309 and 331: The authors give two slightly different water contents for the Erebus lavas. Is the $0.2 \mathrm{wt} \%$ also based on Moussalam et al?

Authors reply:

The mean value in the superficial plumbing system is of $0.2 \mathrm{wt} \%$, and the most hydrous phonolites (at depth) present a water content that can reach $0.6 \mathrm{wt} \%$. This is implied as in the first case we clearly speak of the lava lake, and in the second case of the tephriphonolite to phonolite evolution trend. All values were published in the cited papers.

We modified the text to reflect this and make things clearer.

\section{Reviewer's comment:}

Figure 5: The authors report Di from rhyolitic compositons. Can the authors precise how different they may be for a phonolitic composition?

Authors reply:

We did not find lots of data regarding diffusion experiments. Most of them were done on rhyolites, a few on basalts, and also on simplified compositions. Rhyolites are richer in silica and depleted in alkaline-earth elements compared to phonolites. However, both present an important fraction of alkali elements, which drive redox exchanges at temperatures close to $\mathrm{Tg}$. This is why we have chosen to plot $\mathrm{D}$ values from rhyolites in this case (also because $D$ values on phonolites do not exist...)

We added a comment to clarify such choice in the text, see lines 493-504.

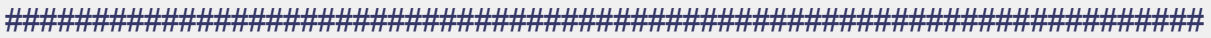
\#\#\#\#\#\#\#\#\#

\#\#\# Reviewer \# 3

Reviewer's comment:

My main request is to have more detail on the experimental and analytical set-up, and for supplementary data to be provided.

Authors reply: 
We thank the reviewer for the comments that helped improving this part of the manuscript.

The new version of the manuscript comes with an updated Material and Methods section, supplementary figures presenting the XANES standard for the centroid versus integrated intensity diagram, examples of Raman spectra of starting materials and of successful runs and failed experiments, and examples of pre-edge modelling. We hope that those new pieces of information will fulfil the reviewer expectation.

Reviewer's comment:

"Iron redox and environment" - title, L24, L36

The term "environment" is here used as a way to summarize the variables of temperature and atmospheric gas composition, both of which are controlled in the experiment set-up. I think the title is a little misleading: as it is worded, it implies that the paper is a dynamic study of environment, but actually the "environment" variables are being controlled and what is being studied is the response to the changing environment in iron redox and co-ordination number. Could the title and phrasing in L24, L36 be modified slightly to reflect this? E.g. L24 "In such cases, little is known about the behaviour of iron redox in response to a rapidly changing magmatic environment".

Authors reply:

We understand that the term "environment" leads to some confusion as it could refer to $\mathrm{T}$-fO2 as stated by the reviewer, but by iron environment we actually meant iron molecular environment.

This is now clarified by the new version of the title, where we replaced environment by coordination. This was also changed in the abstract.

\section{Reviewer's comment:}

l'd consider pressure to be an "environmental" variable relevant to natural magmatic systems. Please add a sentence somewhere near the beginning explaining that $P$ is an intensive variable that does change in natural systems, even though this particular study is conducted at constant $P$. Do the authors expect that pressure would also have some effect on iron speciation and co-ordination number? It would be interesting for the authors to comment on what effect (or not) pressure might be expected to have. The biggest pressure effect might be outgassing of redox-sensitive volatiles like sulfur, so this could usefully be added to the discussion section around L340.

\section{Authors reply:}

The effect of pressure is actually know for iron: it promotes higher coordinated species (e.g. see Sanloup 2016 Chemical Geology 429:51 and references cited therein) and forces iron to go in a 2+ valence as pressure increases (e.g. O'Neill et al., 2006, American Min. 91:404).

However, you have to go to the GPa range to see effects, at pressure higher than those of the superficial Erebus plumbing system. Furthermore, we just cannot perform the same experiments under pressure. This is why all the discussion is geared toward the lava lake and the superficial plumbing system.

We included a paragraph on the effect of pressure in the Discussion (see lines 530539), thanks for the wise suggestion.

\section{Reviewer's comment:}

Experimental methods

I would like to see a brief summary of the preparation of the starting material. Is it prepared by crushing the bulk sample including the 30 vol. \% anorthoclase phenocrysts? 


\section{In situ XANES study of the influence of varying temperature and oxygen} fugacity on iron oxidation state and coordination in a phonolitic melt

Charles Le Losq ${ }^{1,2 *}$, Roberto Moretti ${ }^{1,3}$, Clive Oppenheimer ${ }^{4}$, François Baudelet ${ }^{5}$, Daniel R.

Neuville $^{1}$

5

${ }^{1}$ Université de Paris, Institut de physique du globe de Paris, UMR 7154 CNRS, 75005 Paris, France

${ }^{2}$ Research School of Earth Sciences, The Australian National University, Building 142, Mills Road, Acton, ACT 2601,

Australia.

${ }^{3}$ Observatoire Volcanologique et Sismologique de Guadeloupe, Institut de Physique du Globe de Paris, 97113 Gourbeyre, France

${ }^{4}$ Department of Geography, University of Cambridge, Downing Place, Cambridge, CB2 3EN, United Kingdom.

${ }^{5}$ SOLEIL Synchrotron

*Corresponding author: lelosq@ipgp.fr

ORCID numbers:

Charles Le Losq: 0000-0001-8941-9411

Roberto Moretti: 0000-0003-2031-5192

Clive Oppenheimer: 0000-0003-4506-7260

Daniel R. Neuville: 0000-0002-8487-5001 


\section{Abstract}

$1^{21}$

${ }_{3}^{2} 22$

${ }_{5}^{4} 23$

624

Iron oxidation state and environment in magmas affect their phase diagram and their properties, including viscosity and density, which determine magma mobility and eruptive potential. In turn, magma composition, pressure, temperature and oxygen fugacity affect iron oxidation state and coordination, potentially leading to complex feedbacks associated with magma ascent, degassing and eruption. While equilibrium experiments and models have led to a deep understanding of the role of iron in melts, our knowledge of the effects of disequilibrium processes on iron oxidation state and its structural role in lavas and magmas remains limited. Accordingly, we performed a series of dynamic disequilibrium experiments on a natural melt composition (a phonolite lava from Erebus volcano, Antarctica) at atmospheric pressure, in which oxygen fugacity and temperature were controlled and varied. During the experiments, we continuously measured iron oxidation and coordination using Fe K-edge dispersive X-ray Absorption Spectroscopy (XAS). We found that iron oxidation state changes in the phonolite melt are reversible and well reproduced by existing models. Changes in iron oxidation state are driven by joint diffusion of alkali cations and oxygen anions at magmatic temperatures $\left(\sim 1000{ }^{\circ} \mathrm{C}\right.$ for Erebus phonolite). However, redox diffusion timescales are too slow for any significant oxygen exchange with the atmosphere at the lava/air interface or via air entrainment. Turning to iron coordination, while $\mathrm{Fe}^{2+}$ and $\mathrm{Fe}^{3+}$ are present mostly in an average five-fold coordination, complex coordination variations decoupled from redox changes were detected. The data suggest transitions between $\mathrm{Fe}^{3+}$ in four-fold and six-fold coordination prior to reduction or as a consequence of oxidation. This questions the possible implication of Fe coordination changes in triggering crystallisation of magnetite nanolites upon magma ascent, and, through such crystallisation events, in promoting magma explosivity.

Keywords: magmas, iron, oxidation state, coordination, XANES spectroscopy, volcano

\section{Declarations}

\section{Funding}

We acknowledge SOLEIL (Gif sur Yvette, France) for provision of synchrotron radiation facilities (proposal 20101038). CLL acknowledges support received from the Australian Research Council Laureate Fellowship (FL130100066) of Hugh St.C. O’Neill as well as from the Chaire d'Excellence of the University of Paris during data processing and manuscript preparation. $\mathrm{CO}$ acknowledges support from the Natural Environment Research Council (grant NE/N009312/1). 
155 Conflicts of interest/Competing interests

2

${ }_{4}^{3} 56$ Not applicable

5

657

7

${ }_{9}^{8} 58$ Availability of data and material

10

$11^{5}$

12 $13^{60}$

14

1561

16

17

$18^{62}$

19

2063 Not applicable

21

${ }^{22} 64$

23

2565

26

2766

All data are available in this manuscript and in Supplementary Materials. Raw data are available upon request to the corresponding author.

\section{Authors' contributions}

CO collected the samples for analysis. CLL, RM, CO and DN designed the study. CLL, RM, FB and DN performed the XANES experiments. CLL processed the data and drafted the manuscript. All authors contributed to the final version of the manuscript. 


\section{Introduction}

The importance of iron in magmatic systems has prompted many studies concerning its environment and oxidation state in lavas and magmas (e.g. Berry et al., 2003; Wilke et al., 2004; O’Neill et al., 2006; Cottrell et al., 2009; Giuli et al., 2012; Zhang et al., 2018; Berry et al., 2018, O’Neill et al., 2018), its effects on their rheology (e.g. Dingwell and Virgo, 1987; Dingwell, 1991; Chevrel et al., 2013, 2014) and its structural role in melts and glasses (e.g. Fox et al., 1982; Mysen et al., 1985; Cooney and Sharma, 1990; Wang et al., 1995; Magnien et al., 2004, 2006, 2008; Cicconi et al., 2015a,b). Iron can exist in melts in two valence states $\left(\mathrm{Fe}^{2+}\right.$ and $\left.\mathrm{Fe}^{3+}\right)$ that have different effects on melt physico-chemical properties. In particular, iron affects the density and viscosity of silicate melts. For instance, increasing the relative fraction of $\mathrm{Fe}^{2+}$ in an iron-bearing sodium silicate melt decreases viscosity by nearly an order of magnitude at constant temperature (Dingwell and Virgo, 1988). Changes in iron oxidation state also affect melt density because of the different partial molar volumes of $\mathrm{FeO}$ and $\mathrm{Fe}_{2} \mathrm{O}_{3}$, thereby influencing magma mobility and explosivity (see the reviews of Gonnermann et al., 2013; Gonnermann 2015; and Le Losq et al., 2020 and references cited therein).

Previous studies of iron redox state in quenched glasses (e.g. Kilinc et al., 1983; Kress and Carmichael, 1991; Sack et al., 1980; Wilke et al., 2001, 2004, Berry et al., 2003; O'Neill et al. 2006; Cottrell et al., 2009; Giuli et al., 2012; Cicconi et al., 2015a) or, more recently, in silicate melts via high temperature X-ray Absorption (XAS) spectroscopy (Magnien et al., 2004, 2006, 2008; Métrich et al., 2006; Wilke et al., 2007a,b; Cochain et al., 2013; Drewitt et al., 2013; Cicconi et al. 2015b; Alderman et al., 2017; Bidegaray et al., 2018) have shown that the iron oxidation state in silicate melts is driven by temperature, oxygen fugacity, pressure and melt chemical composition. Accordingly, the effects of iron on the structure and properties of silicate melts are complex functions of those parameters.

Both parametric (e.g. Kress and Carmichael, 1991; Jayasurika et al., 2004; Borisov et al., 2018) and thermochemical (Ottonello et al., 2001; Moretti, 2005) models permit estimation of the iron redox state, hereafter expressed as $\mathrm{Fe}^{3+} / \mathrm{Fe}^{\mathrm{TOT}}$ where $\mathrm{Fe}^{\mathrm{TOT}}=\mathrm{Fe}^{2+}+\mathrm{Fe}^{3+}$, as a function of temperature, oxygen fugacity and melt chemical composition. Such models are mostly based on analyses of experimental glasses formed by quenching silicate melts equilibrated at given conditions (e.g. Kress and Carmichael, 1991). However, such data do not provide insights into dynamic changes likely to be occurring at high temperature in the molten state in magmatic systems. Such processes can however be studied in situ (i.e, at high temperature in the liquid state) through Fe K-edge X-Ray 
Absorption Near Edge Structure (XANES) spectroscopy (Magnien et al., 2004, 2006; Métrich et al., 2006; Wilke et al. 2007a,b; Magnien et al. 2008; Cochain et al., 2013; Cicconi et al. 2015a, Bidegaray et al., 2018). This approach can shed light on how iron oxidation state and coordination number $(\mathrm{CN})$ are affected by dynamic changes in intensive variables in natural lavas. Furthermore, in situ XANES experiments avoid the problem of photoreduction of iron (Gonçalves Ferreira et al., 2013), which may compromise data acquired on glasses at room temperature (Gonçalves Ferreira et al., 2013; Cottrell et al., 2018)

In this study, we leverage the dispersive setup of the ODE beamline at SOLEIL to obtain "snapshot" Fe K-edge XANES spectra of an aluminosilicate melt of phonolitic composition from a natural sample (a lava bomb) collected near the summit of Mt Erebus, Antarctica, in situ at high temperature. As the only volcano presently erupting phonolitic lavas, and with an extensive body of studies of its magmatic differentiation (e.g., Kyle et al., 1992; Oppenheimer et al., 2011; Iacovino et al., 2016), degassing (e.g., Oppenheimer et al., 2008) and eruptive style (e.g., Aster et al., 2003; Peters et al., 2018), Erebus serves as something of an archetype for alkaline magmatism. Because of this and as alkali diffusion becomes an important process in iron redox mechanisms in silicate melts below liquidus temperatures, the Erebus phonolite composition appeared to be particularly suited and interesting for performing the in situ experiments. We acquired spectra continuously with timesteps of hundreds of ms to $2 \mathrm{~s}$ enabling us to track the influence of changes in temperature or oxygen fugacity. Our primary aim is to improve understanding of how dynamically-changing intensive variables influence the Fe oxidation state and $\mathrm{CN}$.

\section{Material and Methods}

\section{Samples}

The starting material was prepared from a lava bomb sampled on the flanks of Erebus volcano, Antarctica, renowned for its long-lived lava lake. The phonolitic lava contains around 30 vol\% phenocrystals of anorthoclase and minor (less than a few \%) microlites of olivine, clinopyroxene, magnetite and apatite, all held within a glassy matrix. Such a texture is typical of the lava bombs ejected from the crater by the sporadic rupture of large gas bubbles at the lava lake surface.

Preparation of the crystal-free starting material is detailed in Le Losq et al. (2015), which focused on evaluation of the viscosity of the Erebus phonolite magma. Briefly, we examined whole rock samples. A representative portion of $\sim 100 \mathrm{~g}$ of the sample was selected, and then cleaned in an 
ultrasonic ethanol bath for $1 \mathrm{~h}$. The sample was then crushed in an agate mortar and heated for $12 \mathrm{~h}$ at $473 \mathrm{~K}$. The resulting powder was weighed, and then melted in a platinum crucible at $1470 \mathrm{~K}$. The crucible was quenched in water and weighed in order to determine the water loss between 473 and 1470 K. Samples were next heated at 1800 K. The melts were quenched in water and the resulting glasses were weighed again to quantify any further losses between 1470 and $1870 \mathrm{~K}$. The obtained glass was crushed in an agate mortar for $1 \mathrm{~h}$, and heated again in the crucible at $1870 \mathrm{~K}$. This procedure was repeated a further two times.

Finally, four successive melting, quenching and grinding operations were performed in order to obtain an homogeneous glass. The glass density $\left(2.534(6) \mathrm{g} \mathrm{cm}^{-3}\right.$ ) was measured using Archimedes' principle using toluene, and its chemical composition was determined using a Cameca SX50 electron microprobe, with a $10 \mu \mathrm{m}$ beam diameter, $40 \mathrm{nA}$ current, $15 \mathrm{kV}$ acceleration voltage, and 5 $\mathrm{s}$ counting time. The composition of the starting glass is 57.4(4) $\mathrm{wt} \% \mathrm{SiO}_{2}, 0.96(13) \mathrm{wt} \% \mathrm{TiO}_{2}$, 19.8(2) wt $\% \mathrm{Al}_{2} \mathrm{O}_{3}, 5.3(2) \mathrm{wt} \% \mathrm{FeO}, 0.2(2) \mathrm{wt} \% \mathrm{MnO}, 0.89(5) \mathrm{wt} \% \mathrm{MgO}, 2.6(1) \mathrm{wt} \% \mathrm{CaO}, 7.0(3)$ $\mathrm{wt} \% \mathrm{Na}_{2} \mathrm{O}$ and $4.6(2) \mathrm{wt} \% \mathrm{~K}_{2} \mathrm{O}$ (numbers in parentheses are $1 \sigma$ analytical errors).

\section{In situ XANES spectroscopy at the iron K-edge}

In situ XANES measurements at the iron K-edge were performed on the energy-dispersive ODE beamline at the SOLEIL synchrotron facility, France. This bending magnet beamline is equipped with primary vertical focussing bent specular mirror and a horizontal focussing bent crystalline Si (311) polychromator. The detector is a Princeton CCD camera of $400 \times 1240$ pixels. With a $500 \mathrm{~mA}$ stored current the flux on the sample is around $2 \times 10^{7}$ photon/ $\mathrm{s} / \mathrm{eV}$. This setup allows acquisition of Fe K-edge absorption spectra between 7080 and $7250 \mathrm{eV}$ with a resolution of $\pm 0.2 \mathrm{eV}$ in a single shot in less than $2 \mathrm{~s}$. Data acquisition timesteps were adjusted to optimise the observed signal to noise ration and varied between $250 \mathrm{~ms}$ and $2 \mathrm{~s}$. Beam size was approximately $30 \mu \mathrm{m}$ by $30 \mu \mathrm{m}$ FWHM. Energy calibration of the monochromator was made with a metallic iron reference foil, setting the first inflexion point in the Fe K-edge spectrum to $7112 \mathrm{eV}$. Reference spectra on this material were acquired before and after each run to correct for any drift.

Samples were heated using a platinum wire, following the idea of Mysen and Frantz (1992). The relationship between the electrical current intensity in the Pt wire, $I$, and the wire temperature, $T$, was predetermined through melting salts of known fusion temperatures: $\mathrm{KNO}_{3}\left(337^{\circ} \mathrm{C}\right), \mathrm{Ba}\left(\mathrm{NO}_{3}\right)_{2}$ $\left(592{ }^{\circ} \mathrm{C}\right), \mathrm{Li}_{2} \mathrm{CO}_{3}\left(723{ }^{\circ} \mathrm{C}\right), \mathrm{NaCl}\left(801{ }^{\circ} \mathrm{C}\right), \mathrm{K}_{2} \mathrm{SO}_{4}\left(1069{ }^{\circ} \mathrm{C}\right), \mathrm{Li}_{2} \mathrm{SiO}_{3}\left(1204{ }^{\circ} \mathrm{C}\right), \mathrm{CaMgSi}_{2} \mathrm{O}_{3}$ $\left(1391{ }^{\circ} \mathrm{C}\right)$, and $\mathrm{CaSiO}_{3}\left(1544{ }^{\circ} \mathrm{C}\right)$. Temperature was further monitored during experiments with an optical pyrometer. With this setup, temperature could be varied from $500 \mathrm{~K}$ up to $2000 \mathrm{~K}$ with a 
precision of $\pm 10 \mathrm{~K}$ (Neuville et al., 2014 and references therein). The furnace was equipped with an enclosure and a gas-flow system to control oxygen fugacity by fluxing different gases, i.e. $\mathrm{O}_{2}\left(f \mathrm{O}_{2}=\right.$ 1 bar), air $\left(f O_{2}=0.21\right.$ bar), $\mathrm{N}_{2}\left(f O_{2} \sim 10^{-6}\right.$ bar $)$ and $\mathrm{ArH}_{2}\left(f O_{2} \sim 10^{-15}\right.$ bar $)$. With this setup, desired temperatures were reached within seconds, while $\mathrm{fO}_{2}$ in the furnace enclosure could be varied from one equilibrium gas to another in less than $\sim 2-3 \mathrm{~min}$, as the furnace volume is $\sim 0.25 \mathrm{dm}^{3}$ and the gas flux a few $\mathrm{L} \mathrm{min}^{-1}$. Accordingly, temperature and $\mathrm{fO}_{2}$ variations can be considered instantaneous with respect to the typical times, of a few minutes to several hours, required to vary $\mathrm{Fe}^{3+} / \mathrm{Fe}^{\mathrm{TOT}}$ and Fe coordination number $(\mathrm{CN})$ in the melts.

The goal of the experiments was to observe changes in the Fe K-edge XANES spectra following variations in temperature and $\mathrm{fO}_{2}$. We did so by recording spectra through time for different runs during which $\mathrm{T}$ and/or $\mathrm{fO}_{2}$ were varied. Each run involved loading powder of the starting glass material in the hole of the platinum wire. Then, the sample was first heated for more than $10 \mathrm{~min}$ above $1600{ }^{\circ} \mathrm{C}$ in air to ensure removal of any crystals that could form upon initial heating. We acquired a spectrum at those initial conditions, then adjusted the temperature to the desired starting value. The sample was held at the desired starting temperature for more than $30 \mathrm{~min}$ to ensure attainment of equilibrium. Then, each dynamic experiment was initiated by suddenly varying $T$ and/or $\mathrm{fO}_{2}$, and spectra were recorded continuously through time (i.e. a spectrum was acquired every $250 \mathrm{~ms}$ to $2 \mathrm{~s}$ depending on the initial chosen data acquisition setup). All runs were terminated by acquiring a spectrum at $1600^{\circ} \mathrm{C}$ in air, in order to detect any change in the Fe K-edge XANES signal that would indicate changes in the iron chemical composition of the melt (e.g., precipitation of $\mathrm{Fe}$, crystallization, etc.).

During such high temperature experiments, two main problems can occur: loss of alkali elements and metallic iron precipitation on the Pt wire under a reducing atmosphere like that imposed by the $\mathrm{Ar}-\mathrm{H}_{2}$ gas. It is thus necessary to analyse the melts after quench. However, in the present case, microprobe analysis was impossible to perform because the quenched samples were contained in the platinum wires that are re-used for other experiments (after cleaning in HF). To circumvent this problem, we adopted the following strategy:

- We monitored the edge absorption value during data acquisition since iron loss is directly evident in XAS spectra as a decrease of the edge intensity.;

- Noisy XAS signals with intermittent high-frequency features are characteristic of crystallisation. In parallel with the edge absorption value, we thus monitored the appearance of such beyond the edge during experiments;

- Unfortunately, loss of alkalis is not detectable during the XAS analysis but we limited the 
likelihood of it occurring by working mostly below $1550{ }^{\circ} \mathrm{C}$, a temperature very close to that of the synthesis of the original glass at which alkali loss was not observed, and keeping the time at temperatures above $1550^{\circ} \mathrm{C}$ as short as necessary $(10-15 \mathrm{~min})$.

- After the experiments, optical and Raman analysies were performed on the glasses as an additional check further for iron precipitation, crystallisation and chemical changes (e.g. Le Losq et al. 2019).

Here, we report only experiments for which, (i) XAS signals show no visible signs of iron loss or nano-crystallisation, and (ii) post-experimental observations are consistent with the initial glass optical quality and Raman signal (see Supplementary Figure 1). We encountered systematic problems after $\sim 15 \mathrm{~min}$ in the $\mathrm{Ar}-\mathrm{H}_{2}$ atmosphere, with precipitation of $\mathrm{Fe}$ and/or crystallisation. Accordingly, we limit our presentation of results to those that used air or $\mathrm{N}_{2}$. Unfortunately, no viable results for the dynamic experiments with the $\mathrm{Ar}-\mathrm{H}_{2}$ gas can be reported (except single-shot spectra taken quickly after heating and iron reduction, as shown in Fig. 1B).

Fe precipitation was also detected at temperatures above $\sim 1550{ }^{\circ} \mathrm{C}$ for some of the experiments in the $\mathrm{N}_{2}$ atmosphere. However, no Fe precipitation was observed in air, even after heating the samples at $1630{ }^{\circ} \mathrm{C}$ for $15-20 \mathrm{~min}$ (Fig. 1A). More generally, above $1120{ }^{\circ} \mathrm{C}$, no crystallisation was observed in the melts. Furthermore, after heating samples for $30 \mathrm{~min}$ at $1550{ }^{\circ} \mathrm{C}$ in air, the Raman spectra remain similar to those of the initial glass (Supplementary Figure 1), indicating that no significant chemical change has occurred. Consequently, we further focus on reporting longduration experiments performed at temperatures below $1550{ }^{\circ} \mathrm{C}$, as alkali loss should be very limited under such conditions. Among seven runs that were performed, three meet the aforementioned criteria and are reported below.

\section{XANES data reduction protocol}

The aim of this study is to calculate precisely the centroid (or 'energy barycenter') and integrated intensity (area under the curve) of the iron XAS pre-edge near $7114 \mathrm{eV}$, corrected from a background, as these variables can be used to determine iron oxidation state and speciation in glasses and melts (Wilke et al., 2001, 2004; Berry et al., 2003; Magnien et al., 2004; Cottrell et al., 2009; Cicconi et al., 2015a; Fiege et al., 2017). Indeed, Wilke et al. (2001) established a centroid versus integrated intensity (CII) diagram using mineral standards, which permits evaluation of the mean coordination numbers of $\mathrm{Fe}^{2+}$ and $\mathrm{Fe}^{3+}$ in minerals. In the CII diagram (see Supplementary Figure 2), reference points are indicated and correspond to the values for $\mathrm{Fe}^{2+}$ and $\mathrm{Fe}^{3+}$ in $\mathrm{CN} 4$ to 6 , and the trends observed when changing the oxidation state of iron between those values are 
represented by dashed lines. The CII diagram of Wilke et al. (2001) was originally implemented for minerals, and then revised by Wilke et al. (2004) for glasses using appropriate standards. Alternative data reduction protocols have also been developed (e.g. Giuli et al., 2012).

Choice of protocol (in particular the selection of the pre-edge baseline) is important since it affects the numerical values of centroids and integrated intensities. Here, we apply the data reduction protocol implemented by Cochain (2009; see also Cochain et al., 2009, 2013, and description below). Spectra of $\mathrm{Fe}^{2+}$ (Gillepsite, Grandidierite, Kirschteinite, Hedenbergite) and $\mathrm{Fe}^{3+}$ (Orthoclase, Yoderite, Hematite, Epidote) mineral standards from Cochain (2009) were processed using the scheme described below in order to implement an updated CII diagram (Supplementary Figure 2).

To determine pre-edge centroid and integrated intensity with precision, we modelled the pre-edge as the sum of a background and two pseudo-voigt functions as developed by Cochain (2009) and also presented in Cochain et al. (2009, 2013). For the background, an exponential function of the type $y$ $=\mathrm{A} \exp \left(\mathrm{B}\left(e-e_{o}\right)\right)$ is chosen. The two pseudo-voigt functions are fitted to the observed signal with an equal full-width-at-half-maximum and a fixed energy difference of $1.5 \mathrm{eV}$, in agreement with recommendations from Wilke et al. (2001) and Berry et al. (2018). This ensures robustness and reproducibility of the peak fitting protocol. An example of fit is provided in Supplementary Figure 3, together with histograms of the posterior probability distribution for the calculated pre-edge centroid and integrated intensity. From the fits of six spectra of the melts with a Hamiltonian Monte Carlo algorithm, covering the full encountered range of redox conditions, the maximum standard deviations of the calculated centroid and integrated intensity follow gaussian distributions and are systematically lower than $0.05 \mathrm{eV}$ and $2 \%$ at the $1 \sigma$ confidence interval, respectively. This fitting protocol thus has the advantage of being robust and highly reproducible, which is desirable for in situ data that can present variable signal-to-noise ratios within a single run. Systematic fits of data series (composed of hundreds to thousands of spectra) were performed with a MATLAB script using the lsqcurvefit function (for non-linear least square fits) with the same starting conditions. 


\section{Results}

Before reporting the results of the dynamic runs, we introduce the spectra acquired in air at equilibrium conditions. These illustrate how the Fe K-edge XANES signal changes with changing temperature at air $f \mathrm{O}_{2}$, and, hence iron oxidation state in the melt. At air $f \mathrm{O}_{2}$, the Fe K-edge in XANES spectra shift towards lower energy with increasing temperature (Fig. 1A), a variation typical of iron reduction in aluminosilicate melts (e.g. Berry et al., 2003; Wilke et al., 2004). The shape of the pre-edge also changes with increasing $T$ from $1100{ }^{\circ} \mathrm{C}$ to $1630{ }^{\circ} \mathrm{C}$ at air $f \mathrm{O}_{2}$ (insert in Fig. 1A), indicating variations in the melt $\mathrm{Fe}^{3+} / \mathrm{Fe}^{\mathrm{TOT}}$. For the conditions reported in Fig. 1A, since the $\mathrm{Fe}^{3+}$ pre-edge has a greater integrated intensity than the $\mathrm{Fe}^{2+}$ pre-edge, the dominant $\mathrm{Fe}$ valence in the melt must have been 3 . At constant $T$ but varying $f \mathrm{O}_{2}$ (air, $\mathrm{N}_{2}, \mathrm{Ar}-\mathrm{H}_{2}$ ), the pre-edge shape changes strongly (Fig. 1B), with the appearance of a contribution near $7113 \mathrm{eV}$ that clearly indicates the reduction of $\mathrm{Fe}$, until $\mathrm{Fe}^{2+}$ dominates under $\mathrm{Ar}-\mathrm{H}_{2}$ atmosphere $\left(f \mathrm{O}_{2} \sim 10^{-15}\right)$.

Fig. 2 shows how the pre-edge integrated intensity and centroid change with time after a sudden increase in $T$ from $1100{ }^{\circ} \mathrm{C}$ to $1420{ }^{\circ} \mathrm{C}$ at constant $f \mathrm{O}_{2}$, in a $\mathrm{N}_{2}$ atmosphere $\left(f \mathrm{O}_{2} \sim 3.5 \times 10^{-6}\right)$. This sudden increase in $T$ leads to a logarithmic decrease in the pre-edge centroid, indicating a logarithmic decrease in $\mathrm{Fe}^{3+} / \mathrm{Fe}^{\text {TOT }}$ with time (Fig. 2B; Wilke et al., 2001). The CII diagram suggests that the mean $\mathrm{CNs}$ of $\mathrm{Fe}^{2+}$ and $\mathrm{Fe}^{3+}$ are $\sim 5$, and do not change significantly with $T$, hence $\mathrm{Fe}^{3+} / \mathrm{Fe}^{\mathrm{TOT}}$.

The ability to change $\mathrm{T}$ and $\mathrm{fO}_{2}$ either simultaneously or consecutively during experiments allowed us to perform more complex, dynamic experiments. Figure 3 illustrates an experiment with a path composed of multiple $T$ - $f \mathrm{O}_{2}$ combinations. We first started with a melt in equilibrium with $\mathrm{O}_{2}$ gas at $1115{ }^{\circ} \mathrm{C}\left(f \mathrm{O}_{2} \approx 1\right)$, and then, in step (1) suddenly increased $T$ to $1330{ }^{\circ} \mathrm{C}$ and decreased $f \mathrm{O}_{2}$ to that of $\mathrm{N}_{2}$ gas $\left(f \mathrm{O}_{2} \sim 3.5 \times 10^{-6}\right)$. We see a non-linear decay of the pre-edge centroid, indicating a reduction of the melt, as expected. A second step (2) was made, in which $T$ was decreased to $1120{ }^{\circ} \mathrm{C}$ and $f O_{2}$ switched to that of $\mathrm{O}_{2}$ gas $\left(\mathrm{fO}_{2} \approx 1\right)$. In this case, the pre-edge centroid increases, describing a logarithmic trend with time (Fig. 3B). Step 3 consisted of increasing $T$ to $1400{ }^{\circ} \mathrm{C}$ while changing $\mathrm{fO}_{2}$ from that of $\mathrm{O}_{2}$ gas to that imposed by $\mathrm{N}_{2}$ gas. A sudden decrease of the pre-edge centroid is observed (Fig. 3B). During step 4, we kept $f \mathrm{O}_{2}$ to that of $\mathrm{N}_{2}$ but increased $T$ to $1500{ }^{\circ} \mathrm{C}$; a small and rapid decrease of the pre-edge centroid is observed, which then quickly stabilized around $7113.6 \mathrm{eV}$ (Fig. 3B). Finally (step 5), we decreased $T$ to $1130{ }^{\circ} \mathrm{C}$ at $f \mathrm{O}_{2}$ imposed by pure $\mathrm{N}_{2}$, resulting in a progressive increase of the pre-edge centroid, indicating a final oxidation of $\mathrm{Fe}$ at this lower temperature. We notice that this step 5 is characterized by a slow change of the pre-edge centroid, 
describing a logarithmic trend again, but a plateau was not attained indicating that the experiment was concluded before reaching equilibrium.

The integrated intensity of the pre-edge changed in tandem with the centroid during the multi-step run presented in Fig. 3. Variations in steps 1 and 2 fall on a mean $\mathrm{Fe}^{2+} \mathrm{CN} 5-\mathrm{Fe}^{3+} \mathrm{CN} 5$ trend in the CII diagram (Fig. 3A). Variations in steps 3, 4 and 5 depart from this trend and indicate the occurrence of $\mathrm{Fe}^{2+}$ and $\mathrm{Fe}^{3+}$ in CN6. In particular, at the beginning of step 4 (pink symbols in Fig. $3 \mathrm{~A}$ ), measurements in the $\mathrm{CII}$ diagram fall on the $\mathrm{Fe}^{2+} \mathrm{CN} 6-\mathrm{Fe}^{3+} \mathrm{CN} 6$. This changes with time during step 4 , and measurements at the beginning of step 5 fall back on a $\mathrm{Fe}^{2+} \mathrm{CN} 5-\mathrm{Fe}^{3+} \mathrm{CN} 5$ trend. They evolve again toward a $\mathrm{Fe}^{2+} \mathrm{CN} 6-\mathrm{Fe}^{3+} \mathrm{CN} 6$ trend upon oxidation in step 5 (Fig. 3A).

A final successful run allowed us to acquire data following a simple $T$ decrease from $1550{ }^{\circ} \mathrm{C}$ to $1150{ }^{\circ} \mathrm{C}$ at constant $f \mathrm{O}_{2}(0.21$; on air). During this run, we observed a logarithmic increase of the pre-edge centroid with time, and a non-linear evolution of the integrated intensity versus centroid relationship (Fig. 4). This indicates that, while $\mathrm{Fe}^{3+} / \mathrm{Fe}^{\text {TOT }}$ is slowly increasing following the temperature change (Fig. 4B), Fe coordination changes rapidly at first and then stabilizes after some time (Fig. 4A). These data suggest that the $\mathrm{Fe}^{3+}$ mean coordination is slightly less than 5, while the $\mathrm{Fe}^{2+}$ mean $\mathrm{CN}$ lies between 5 and 6 .

Data obtained at equilibrium conditions and reported in Figures 1 to 4 can be used to estimate the oxidation state of iron. Several methods are reported in the literature (e.g. see Berry et al., 2004; Wilke et al., 2004; Cottrell et al. 2009; Fiege et al., 2017; Berry et al., 2018; Zhang et al., 2018). Most methods rely on the use of fully oxidized and reduced standards for precision (e.g. Berry et al., 2018, Zhang et al., 2018 and references cited therein). However, this was neither practical nor pertinent in our case as during in situ experiments, the signal changes slightly with temperature (Wilke et al., 2007a). Furthermore, even if we have signals from nearly fully oxidized and reduced melts, we cannot assert that a linear combination of the XANES data, for instance, would provide reliable results. Indeed, as we acquire XANES signals continuously, every $250 \mathrm{~ms}$ to $2 \mathrm{~s}$ depending on the run, the signal to noise ratio varies with acquisition conditions. In particular, Ar absorbs part of the X-ray signal, such that spectra acquired under Ar- $\mathrm{H}_{2}$ conditions are quite noisy (Fig. 1B). Fortunately, the pre-edge is barely affected by temperature (Wilke et al., 2007a) and its centroid remains easy to measure with precision in noisy data (see experimental methods).

Wilke et al. (2004) proposed an equation relating the variations of the pre-edge centroid to changes in iron oxidation state in basaltic glasses, where $\mathrm{Fe}^{2+}$ and $\mathrm{Fe}^{3+}$ were found in CN5. Such a method 
was reviewed by Fiege et al. (2017), who found that Fe oxidation state determination using the preedge centroid position is reliable to within $\pm 6 \%$. As $\mathrm{Fe}^{2+}$ and $\mathrm{Fe}^{3+}$ tend to be generally in CN5 in our system (Figs. 2, 3, 4), we estimated iron redox in our melts using the equation provided by Wilke et al. (2004). Figure 5 presents the results of this exercise. The iron redox state values calculated from the pre-edge centroid agree well with the predictions from the parametric model of Kress and Carmichael (1991), used in the MELTS software (Ghiorso and Sack, 1995), and from the thermodynamic model of Moretti (2005). We only notice a slight shift for the model of Moretti (2005) from data at air $f \mathrm{O}_{2}$; the Kress and Carmichael (1991) model fits well the data at air $f \mathrm{O}_{2}$, and both models agree well with data at $\mathrm{N}_{2} f_{2}$. Both the Kress and Carmichael (1991) and Moretti (2005) models were already tested by Schuessler et al. (2008) and shown to be accurate for phonolites. Therefore, the estimates of the iron redox in the phonolite melts calculated from the preedge centroid and the equation provided by Wilke et al. (2004) are reliable, despite differences in melt compositions, the fact that we are dealing with in situ data on melts, and the potential presence of 6-fold coordinated iron species in our melts (Fig. 3). The standard deviation between the Kress and Carmichael (1991) model (closest to all data) and measured values is equal to 0.04 ( $1 \sigma$, rounded up value); it provides an estimate of the analytical error affecting redox data presented in Figure 5.

\section{Discussion}

\section{Chemical mechanisms of iron speciation and redox behaviour}

Our observations confirm that changes in $\mathrm{Fe}^{3+} / \mathrm{Fe}^{\mathrm{TOT}}$ in phonolite melts are entirely reversible following variations in $\mathrm{T}$ and $\mathrm{fO}_{2}$, in agreement with previous findings from high temperature redox measurements on different melt compositions (Wilke et al., 2007a,b, Magnien et al. 2008, Cicconi et al. 2015b). Furthermore, iron oxidation state in phonolite melts is well described by existing models (Figure 5), consistent with Schuessler et al. (2008). However, the data reveal that changes in $\mathrm{CN}$ are more complex, and not systematically related to oxidation or reduction phenomena (Figs. 2A, 3A, 4A). The reported changes agree, in general, with the studies of Wilke et al. (2007), Cicconi et al. (2015b) or Stabile et al. (2017) that revealed variations in the CII diagram following a $\mathrm{Fe}^{3+} \mathrm{CN} 4-5$ and $\mathrm{Fe}^{2+} \mathrm{CN} 5$ pathway. But looking more closely, complex but subtle changes in $\mathrm{CN}$ are evident (Fig. 4A), together with the possible occurrence of Fe in $\mathrm{CN} 6$ (Fig. 3A).

The discrepancies may arise from the fact that previous studies mostly reported equilibrium values in the CII diagram. Indeed, the dynamic studies of Magnien et al. (2006, 2008), Wilke et al. (2007b), Cochain et al. $(2009,2013)$ or Bidegaray et al. (2018) did not report data in the CII 
377

diagram. To the best of our knowledge, no previous study reported out-of-equilibrium results from dynamic experiments in the CII diagram. Dynamic studies may reveal changes in term of iron $\mathrm{CN}$ that were not foreseen from equilibrium experiments. Indeed, while in the first reported run (Fig. 2A), no change in $\mathrm{CN}$ accompanies the redox change following $T$ increase at constant $f \mathrm{O}_{2}$, in runs 2 and 3, changes in $\mathrm{Fe}^{2+}$ and $\mathrm{Fe}^{3+} \mathrm{CNs}$ are detected and appear to be complex. In one case, decreasing temperature in air is related to a slight but non-linear increase in $\mathrm{Fe}^{3+} \mathrm{CN}$ (Fig. 4A), suggestive of a decoupling of redox and $\mathrm{CN}$ changes under dynamic conditions. In the other case, changing temperature in a $\mathrm{N}_{2}$ atmosphere can be accompanied by a general change of both $\mathrm{Fe}^{3+}$ and $\mathrm{Fe}^{2+} \mathrm{CNs}$ from 5 to 6 (Fig. 3A). Unfortunately, while revealing intriguing trends, the experiments are insufficient to define the underlying mechanisms. We hope they will stimulate future in situ, high temperature experiments.

Our experimental data indicate $\mathrm{Fe}^{3+}$ at a mean $\mathrm{CN}$ of $\sim 5$, but this value will be sensitive to the magmatic environment and any other dynamic redox processes (Figs. 2, 3, 4). Knowledge of how $\mathrm{Fe}^{3+} \mathrm{CN}$ varies with intensive and extensive parameters is important because the structural role of $\mathrm{Fe}^{3+}$, and hence its influence on magmatic properties, will depend on its $\mathrm{CN}$. Indeed, while $\mathrm{Fe}^{3+}$ in $\mathrm{CN} 4$ and 5 acts as a weak network former role, entering the silicate melt polyhedral network, $\mathrm{Fe}^{3+}$ in CN6 may be considered as a network modifier that disrupts the melt structure. Consequently, $\mathrm{Fe}^{3+}$ influence on melt properties is expected to vary with its $\mathrm{CN}$. In the Erebus lava, $\mathrm{Fe}^{3+}$ mean $\mathrm{CN}$ may reflect mostly five-folded $\mathrm{Fe}^{3+}$ (network former) with lesser amounts of four-folded (network former) and six-folded (network modifier) $\mathrm{Fe}^{3+}$, or from a mixture of four-folded and six-folded $\mathrm{Fe}^{3+}$. By performing high temperature in situ XAS experiments on $\left(\mathrm{Fe}_{\mathrm{x}} \mathrm{Ca}_{1-\mathrm{x}} \mathrm{O}\right)_{\mathrm{y}}\left(\mathrm{SiO}_{2}\right)_{1-\mathrm{y}}$ melts, Drewitt et al. (2013) showed that, in such melts, a mixture of 4-fold and 6-fold coordination is entirely plausible. This agrees with previous findings from Mysen et al. (1985), who analysed CaO$\mathrm{MgO}-\mathrm{Al}_{2} \mathrm{O}_{3}-\mathrm{SiO}_{2}-\mathrm{FeO}$ glasses with Mössbauer spectroscopy. If this remains valid for phonolites, our study demonstrates that it is possible that $\mathrm{Fe}^{3+}$ becomes purely a network modifier under reducing conditions, as proposed by Mysen et al. (1985). Indeed, those authors proposed that the coordination of $\mathrm{Fe}^{3+}$ changed with iron oxidation state, $\mathrm{Fe}^{3+}$ in $\mathrm{CN} 4$ being promoted under oxidized conditions and in CN 6 under reduced conditions. This would be consistent with the findings of Drewitt et al. (2013) as already discussed. It would further explain why, under reducing conditions, it is possible to lose the contribution of $\mathrm{Fe}^{3+}$ in $\mathrm{CN} 4$ as seen in Figure $3 \mathrm{~A}$, or, upon oxidation, it is possible to gain a contribution from $\mathrm{Fe}^{3+}$ in $\mathrm{CN} 4$ as suggested by the trend apparent in Figure 4A. Turning to divalent iron, $\mathrm{Fe}^{2+}$ appears five- and even six-fold coordinated in these phonolite melts (Figs. 2-4A). Similar results have been found for basaltic compositions (e.g., Galoisy et al. 2001; Wilke et al. 2004) and phonolitic glasses (Giuli et al. 2012). 
413 Considering the aforementioned changes in coordination as $T$ and $f \mathrm{O}_{2}$ vary, different iron-bearing complexes thus participate in redox exchanges in the melts. These can be polyhedra of trivalent iron in four-fold and five-fold coordination, $\mathrm{Fe}^{\mathrm{III}} \mathrm{O}_{4}^{5-}, \mathrm{Fe}^{\mathrm{III}} \mathrm{O}_{5}^{7-}$, and cationic species $\mathrm{Fe}^{3+}$ and $\mathrm{Fe}^{2+}$ (note that henceforth we will use III to indicate the valence state in anionic complexes and avoid confusion with $\mathrm{Fe}^{2+}$ and $\mathrm{Fe}^{3+}$ cations). $\mathrm{Fe}^{\mathrm{III}} \mathrm{O}_{4}^{5-}$ and $\mathrm{Fe}^{\mathrm{III}} \mathrm{O}_{5}^{7-}$ anionic complexes are true coordination

polyhedra of iron in the sense of Pauling (1960), that is, effective chemical species in which $\mathrm{Fe}-\mathrm{O}$ bonds are strongly covalent. For this reason, iron in these anionic complexes behaves as a network former (Ottonello et al., 2001; Moretti, 2005, 2020). On the other hand, due to their low ionic field strengths, $\mathrm{Fe}^{3+}$ in $\mathrm{CN} 6$ and $\mathrm{Fe}^{2+}$ in $\mathrm{CN} 4$ to 6 do not form true polyhedra, but ionic couplings with surrounding oxygens. In this case, iron behaves as a network modifier. Using the notations, several reactions can be written, all presenting different implications for iron redox and melt structure:

$$
\begin{aligned}
& \mathrm{Fe}^{\mathrm{III}} \mathrm{O}_{4}^{5-}+e^{-} \Leftrightarrow \mathrm{Fe}^{2+}+40^{2-}, \\
& \mathrm{Fe}^{\mathrm{III}} \mathrm{O}_{5}^{7-}+e^{-} \Leftrightarrow \mathrm{Fe}^{2+}+50^{2-} .
\end{aligned}
$$

For redox exchanges involving the cationic species $\mathrm{Fe}^{3+}$ and $\mathrm{Fe}^{2+}$ acting as network modifiers (e.g. in $\mathrm{CN}$ 6), we have:

$$
\mathrm{Fe}^{3+}+e^{-} \Leftrightarrow \mathrm{Fe}^{2+} .
$$

These reactions must be coupled with the so-called 'oxygen electrode' (Ottonello et al., 2001; Moretti, 2005, Moretti and Ottonello, 2005, 2020; Cicconi et al., 2020):

$\frac{1}{2} \mathrm{O}_{2}+2 e^{-} \Leftrightarrow \mathrm{O}^{2-}$,

which links oxygen fugacity to the structural state of the melt through the activity of $\mathrm{O}^{2-}$ (oxide ions, or so-called free oxygens; Fincham and Richardson, 1954; Toop and Samis, 1962; Fraser, 1975; Ottonello et al., 2001; Moretti, 2005; Nesbitt et al., 2015). Free oxygens represent all oxygen anions not associated with the silicate network, i.e., not part of coordination polyhedra around network formers (e.g., $\left.\mathrm{Si}^{4+}, \mathrm{Al}^{3+} \ldots\right)$. They are considered coupled to network modifying cations $\left(\mathrm{Mg}^{2+}\right.$, $\mathrm{Ca}^{2+}, \mathrm{Na}^{+}, \mathrm{K}^{+} \ldots$ ) via ionic bonds (e.g. Nesbitt et al., 2015), and measure the system basicity (Moretti, 2005, 2020).

It must be noted that the adoption of the oxygen electrode is not only required by the theory of aprotic, oxide-based solvents (e.g. Flood and Forland, 1947; Jørgensen, 1969), but, in the context of our experiments, there is no other redox couple able to establish a mutual redox interaction with iron species. Combining this redox couple to reactions 1 to 4 , we can write the following redox equilibria (see also Moretti, 2005):

$\mathrm{Fe}^{\mathrm{III}} \mathrm{O}_{4}^{5-} \Leftrightarrow \mathrm{Fe}^{2+}+\frac{7}{2} \mathrm{O}^{2-}+\frac{1}{4} \mathrm{O}_{2}$ 
446

$\frac{747}{2}$

$\mathrm{Fe}^{\mathrm{III}} \mathrm{O}_{5}^{7-} \Leftrightarrow \mathrm{Fe}^{2+}+\frac{9}{2} \mathrm{O}^{2-}+\frac{1}{4} \mathrm{O}_{2}$,

$\mathrm{Fe}^{3+}+\frac{1}{2} \mathrm{O}^{2-} \Leftrightarrow \mathrm{Fe}^{2+}+\frac{1}{4} \mathrm{O}_{2}$.

According to existing thermodynamic data, these reactions are such that the higher oxidation state is favoured by decreasing temperature (see also Ottonello et al., 2001), consistent with our experimental results (Figure 5). At constant temperature, based on Le Chatelier's principle, reactions 6 and 7 imply that increasing the activity of $\mathrm{O}^{2-}$ increases the iron oxidation state at constant oxygen fugacity (since $\mathrm{O}_{2}$ and $\mathrm{O}^{2-}$ are both on the right side of the equations). This effect has been well known in the glass industry since the 1960s (e.g. Paul and Douglas, 1965; Moretti, 2005, 2020 and references therein): it was observed upon addition of alkali oxides to glass batches, with consequent decrease of silica and melt polymerization, and increase of free oxygens. However, if reaction (8) becomes dominant, iron reduction at constant oxygen fugacity occurs because $\mathrm{O}_{2}$ and $\mathrm{O}^{2-}$ appear on the opposite sides of those equations.

This contrasting behaviour implies that the iron oxidation state is related to melt polymerization in a non-linear way, because $\mathrm{Fe}^{3+}$ may play an amphoteric role, being a network former or network modifier depending on its speciation (see also Ottonello et al., 2001; Moretti, 2005, 2020; Moretti and Ottonello 2005). This amphoteric behaviour is strictly related to bulk melt composition, thus to the chemical differentiation specific to every system, most often driven by fractional crystallization and/or degassing. Therefore, iron redox patterns in magmatic systems may be difficult to interpret because of the combination of contributions from the evolving melt composition and from associated variations in oxygen fugacities. In the case of Erebus, this implies that, in addition to redox changes at constant composition, the basanite to phonolite magmatic differentiation trend should influence the bulk iron redox state of the magma as proposed by Oppenheimer et al. (2011), in addition to other suspected controls such as magnetite precipitation (Oppenheimer et al., 2011) and possibly sulfur degassing (Moussallam et al., 2014) in the shallow regions of the magmatic system.

\section{The role of diffusive mechanisms}

Redox reactions in silicate melts are controlled by three different mechanisms involving the diffusion of $\mathrm{O}^{2-}$, of $\mathrm{O}_{2}$, and of divalent cations (for details see Goldman and Gupta, 1983; Schreiber, 1986; Cooper et al., 1996a, 1996b; Magnien et al., 2008; Cochain et al., 2013). To distinguish between these mechanisms, the in situ data can be used to calculate the redox diffusivity (Magnien et al., 2008). Indeed, the evolution of the Fe K-edge XANES centroid at a time $t, C_{t}$, can be reproduced using expressions of the form (Magnien et al., 2008): 
$C_{t}=\left(C_{t 0}-C_{e q}\right) \exp (-t / \tau)+C_{t 0}$,

with $C_{t 0}$ the centroid at starting time (before perturbation) and $C_{e q}$ that at equilibrium, and $\tau$ a characteristic time. Those parameters can be determined from a least-squares fit of the data presented in Figs. $2 b, 3 b$ and $4 b$. According to Magnien et al. (2008), $\tau$ is related to the time $t_{e q}$ necessary to reach $99 \%$ of the equilibrium value $C_{e q}$, which reflects equilibrium in $\mathrm{Fe}^{3+} / \mathrm{Fe}^{\mathrm{TOT}}$, as: $t_{e q}=-\tau \ln (0.01)$.

The redox diffusivity, which characterises the diffusivity of structural species necessary to allow the Fe redox state to change following a variation in intensive parameters, can then be calculated as:

$\mathrm{D}_{\text {Redox }}=r^{2} / 4 t_{e q}$,

where $r$ is the sample thickness. From Magnien et al. (2008), the thickness of samples in the platinum-wire setup we have used varies at most between 0.1 and $0.5 \mathrm{~mm}$. Taking those values as maximum deviations from a mean around $0.3 \mathrm{~mm}$, and using eqs. 9 to 11 , we calculate $\mathrm{D}_{\text {Redox }}$ with associated errors from the observations made in situ and reported in Figs. 2, 3 and 4.

The results are reported in Table 1 and represented in Fig. 6, where $\mathrm{D}_{\text {Redox }}$ is given as a function of reciprocal $T$. $\mathrm{D}_{\text {Redox }}$ for our phonolite melt agrees with previous values reported for an alkali basalt melt (Fig. 6) by Cochain et al. (2009). They show a trend similar to those of the diffusivities of the alkalis $\mathrm{Na}$ and $\mathrm{K}$, and possibly of $\mathrm{Ca}$ in alkali-rich and silica-rich melts at high temperature (diffusivity values for phonolite melts were not found for the elements of interest, so we consider values for rhyolite melts because they also are alkali-rich melts). In particular, the slopes of $\mathrm{D}_{\text {Redox }}$ versus $T$ and $\mathrm{D}_{\mathrm{Na}} / \mathrm{D}_{K} / \mathrm{D}_{\mathrm{Ca}} / \mathrm{D}_{\mathrm{Mg}}$ versus $T$ are similar, indicating that the activation energy of the redox diffusivity in phonolite melt is similar to that of metal cation diffusivity in silica-rich melts. On the contrary, $\mathrm{D}_{\text {Redox }}$ is much higher than $\mathrm{D}_{02}$, which can be calculated from the phonolite viscosity $\eta(T)$ estimated by Le Losq et al. (2015). Indeed, as viscosity of silicate melts is governed by exchanges of $\mathrm{O}$ atoms between network formers in the melt structure (e.g. Le Losq and Neuville, 2017), $\mathrm{D}_{O 2}$ directly relates to the diffusivity of $\mathrm{O}$ in the melt, $\mathrm{D}_{O}$, which can be estimated with the Eyring equation:

$\mathrm{D}_{O 2}=\mathrm{D}_{O}=k_{b} \mathrm{~T} /(\eta(\mathrm{T}) \lambda)$, where $k_{b}$ is the Boltzmann constant and $\lambda$ the atomic jump distance, taken as $280 \mathrm{pm}$. As $\mathrm{D}_{\text {Redox }}$ ranges between $\mathrm{D}_{O}$ and $\mathrm{D}_{N a} / \mathrm{D}_{K}$ in the temperature range of our experiments $\left(\sim 1100{ }^{\circ} \mathrm{C}\right.$ to 1600 ${ }^{\circ} \mathrm{C}$ ), and considering the high alkali content of the Erebus magma, redox processes in phonolite melts at such temperatures likely involve mainly cationic and anionic diffusions of $\mathrm{O}^{2-}, \mathrm{Na}^{+}$and $\mathrm{K}^{+}$. This supports previous reports highlighting the importance of metal cation diffusivity for redox exchanges in lavas at magmatic temperatures (e.g. Cooper et al., 1996a,b; Magnien et al., 2008). We 
514 infer that, compared with the alkalis, alkaline-earth cations play a secondary role given their low

concentrations in the Erebus phonolite magma.

An important caveat to our study is that, in the natural system, the presence of volatiles should also affect $\mathrm{D}_{\text {Redox. }}$ Water likely plays a limited role because the phonolite in the Erebus lava lake plumbing system is water-poor (between 0.2 and $0.6 \mathrm{wt} \%$ of water are observed in the tephriphonolite to phonolite series; Oppenheimer et al. 2011; Moussallam et al., 2013; 2014). Furthermore, while changes in $\mathrm{S}$ oxidation state can cause significant changes in that of $\mathrm{Fe}$ in a magma due to the large numbers of electrons exchanged in the redox reactions involving sulfur, $S$ diffusion is slow and is not expected to be an important process in transferring electrons over large distances. Indeed, in intermediate to silicic anhydrous melts, S diffuses more slowly than metal cations (e.g., Fig. 6 for rhyolite, see also Behrens and Stelling, 2011 and references therein), with $\mathrm{SO}_{4}{ }^{2-}$ (i.e., the $\mathrm{S}^{6+}$ bearing species ) diffusing even more slowly than $\mathrm{S}^{2-}$ (Behrens and Stelling, 2011; Lierenfeld et al., 2018). Thus, while $S$ degassing accompanied by local redox changes in the melt will cause local changes in iron redox, diffusion of $S$ alone is not an efficient transporter of electrons capable of driving changes in reactions 6 to 10 .

This comment on sulphur degassing invites consideration of its cause and the consequences the later has on iron oxidation state and coordination in the melt. Indeed, sulphur degassing arises from the decrease of pressure upon magma ascent. Pressure also influences iron redox and coordination in silicate melts, but this effect is mostly measurable at the GPa scale (e.g. see the works of O'Neill et al., 2006; Sanloup et al., 2013; Zhang et al. 2017). In the case of Erebus magmatic pressure is not so extreme ( $\sim .5 \mathrm{GPa}$ at the deepest part of the magmatic system; Oppenheimer et al., 2011) and is thus unlikely to affect the oxidation state or coordination of iron in the magmas. Other variables like magma composition, crystallinity and variations in temperature and volatile contents are much more likely to be the key parameters controlling the magma oxidation state (Oppenheimer et al., 2011; Moussallam et al., 2014).

Finally, given the low $\mathrm{D}_{\text {Redox }}$ at estimated magmatic temperatures for Erebus phonolite (Figure 6), which range between $\sim 950$ and $1100{ }^{\circ} \mathrm{C}$ (different methods have yielded disparate results, see Calkins et al., 2008; Burgisser et al., 2012; Moussallam et al., 2013), diffusive processes should be fairly ineffective for any redox re-equilibration in the shallow magmatic system of Erebus, particularly at the surface of the lava lake, which is resurfaced on timescales of around $10 \mathrm{~min}$ (Oppenheimer et al., 2009). On such a timescale, even if no crust formed at the lake surface (in reality, a crust forms instantaneously on exposure of fresh magmalava at the surface due to the very high radiative heat 
losses), an approximate $\mathrm{D}_{\text {Redox }}$ of $10^{-12} \mathrm{~m}^{2} \mathrm{~s}^{-1}$ is estimated for the lava lake (Fig. 6). In this case, redox re-equilibration of the lava could not extend more than a few tens of microns within the melt.

\section{Conclusions}

Our novel in situ dynamic experiments, using XANES spectroscopy to investigate iron oxidation state and coordination numbers in the Erebus phonolite, reveal how diffusive behaviour and iron speciation control the redox evolution of a lava. While $\mathrm{Fe}^{3+}$ appears to be in $\mathrm{CN} 4$ and 6 in the phonolite melt, the $\mathrm{Fe}^{2+}$ coordination number tends to be mostly equal to 5 to 6 . Changes in iron oxidation state are consistent with predictions of thermodynamic and parametric models. Changes in iron coordination number seem more complex under dynamic conditions, when temperature or $f \mathrm{O}_{2}$ are changed abruptly. A decoupling between changes in iron oxidation state and coordination number is observed under the present dynamic conditions, with $\mathrm{Fe}^{3+}$ probably shifting from a $\mathrm{CN} 4$ to 6 as iron reduction proceeds. This agrees with previously reported data and confirms that $\mathrm{Fe}^{3+}$ is an amphoteric cation that behaves as a network former and modifier in the melt structure. More generally, the melt basicity will control iron redox state. As the basicity of the residual melt will change with magma differentiation, it will be one of the mechanisms influencing the redox evolution of a magma upon differentiation.

Our observations allow determination of the redox diffusivity, which represents the diffusion of a redox front within a melt. Redox diffusion is controlled by alkali counter-diffusion, as shown by the diffusion coefficients (Figure 6). It is of the order of $\sim 10^{-12} \mathrm{~m}^{2} \mathrm{~s}^{-1}$ at the temperature of the Erebus lava lake $\left(\sim 1000^{\circ} \mathrm{C}\right)$. Re-equilibration of the lava redox by diffusion is thus unlikely in the plumbing system, such that redox changes close to or at the surface should only be controlled by magmatic process such as crystallization and degassing.

Our experimental setup represents a first step towards improving our understanding of magma redox changes under varying conditions, and of the underlying mechanisms. Extending the approach to other compositions will be valuable as we can expect redox timescales to be compositionally-dependent. Knowledge of such redox timescales within the melt promises new understanding of redox variations associated with disequilibrium processes that are driven by rapidly changing intensive parameters and feedbacks associated with dynamic volcanic phenomena such as explosive magma fragmentation. For instance, our study indicates that magma degassing could trigger rapid changes in iron $\mathrm{CN}$ and oxidation state. Such rapid change could occur during sulfur degassing for instance, and potentially trigger late nucleation and crystallisation of Fe- 
584

bearing nanolites like magnetite, for instance as $\mathrm{Fe}^{3+}$ becomes available in CN6 following local reduction due to sulfur loss. As nanolites appear to play a significant role in increasing the explosive character of magmas through their effect on their rheology (Di Genova et al., 2017), such Fe CN changes could further participate in increasing melt explosivity, in addition to the many other variables at play. This is a hypothesis that remains to be tested, but it highlights the needs for more in situ data to understand iron behaviour under conditions prone to magma crystallisation and degassing, representative of volcanic systems.

\section{Acknowledgements}

We thank Dominique de Ligny and Yves Moussallam for assistance with XANES experiments. We also thank Hans Keppler, Margaret Hartley and two anonymous referees for their constructive comments that led to significant improvements of the manuscript.

\section{References}

Alderman OLG, Wilding MC, Tamalonis A, et al (2017) Iron K-edge X-ray absorption near-edge structure spectroscopy of aerodynamically levitated silicate melts and glasses. Chem. Geol. 453:169-185.

Aster, R., Mah, S., Kyle, P., McIntosh, W., Dunbar, N., Johnson, J., Ruiz, M. and McNamara, S., 2003. Very long period oscillations of Mount Erebus Volcano. Journal of Geophysical Research: Solid Earth, 108(B11).

Baker LL, Rutherford MJ (1996) Sulfur diffusion in rhyolite melts. Contrib Mineral Petrol 123, 335-344.

Behrens H, Stelling J (2011) Diffusion and redox reactions of sulfur in silicate melts. Rev Mineral Geochem 73, 79-111.

Berry AJ, O’Neill HSC, Jayasuriya KD, Campbell SJ, Foran GJ (2003) XANES calibrations for the oxidation state of iron in a silicate glass. Am Mineral 88:967-977.

Berry AJ, Stewart GA, O’Neill HSC, Mallmann G, Mosselmans JFW (2018) A re-assessment of the oxidation state of iron in MORB glasses. Earth Planet Sc Lett 483:114-123.

Bidegaray A-I, Ceglia A, Cicconi MR, et al (2018) An in-situ XANES investigation of the interactions between iron, manganese and antimony in silicate melts. Journal of Non-Crystalline Solids 502:227235.

Borisov A, Behrens H, Holtz F (2018) Ferric/ferrous ratio in silicate melts: a new model for 1 atm data with special emphasis on the effects of melt composition. Contrib Mineral Petrol 173:98.

Borisov, A., Behrens, H., Holtz, F., 2015. Effects of melt composition on $\mathrm{Fe}^{3+} / \mathrm{Fe}^{2+}$ in silicate melts: a step to model ferric/ferrous ratio in multicomponent systems. Contrib Mineral Petrol 169.

Chevrel MO, Baratoux D, Hess K-U, Dingwell DB (2014) Viscous flow behavior of tholeiitic and alkaline Fe-rich martian basalts. Geochim Cosmochim Acta 124:348-365. 
Chevrel MO, Giordano D, Potuzak M, et al (2013) Physical properties of $\mathrm{CaAl}_{2} \mathrm{Si}_{2} \mathrm{O}_{8}-\mathrm{CaMgSi}_{2} \mathrm{O}_{6}-\mathrm{FeO}_{-}$ $\mathrm{Fe}_{2} \mathrm{O}_{3}$ melts: Analogues for extra-terrestrial basalt. Chem Geol 346:93-105.

Cicconi MR, Giuli G, Ertel-Ingrisch W, et al (2015a) The effect of the $[\mathrm{Na} /(\mathrm{Na}+\mathrm{K})]$ ratio on Fe speciation in phonolitic glasses. Am Mineral 100:1610-1619.

Cicconi MR, Neuville DR, Tannou I, et al (2015b) Competition between two redox states in silicate melts: An in-situ experiment at the Fe K-edge and Eu L3-edge. Am Mineral 100:1013-1016.

Cicconi MR, Moretti R, Neuville DR (2020) Earth's Electrodes, Elements (in press)

Cochain B (2009) Cinétique et mécanismes d'oxydoréduction dans les silicates fondus (Ph.D.). Pierre et Marie Curie - Paris VI, Paris.

Cochain B, Neuville DR, de Ligny D, Roux J, Baudelet F, Strukelj E, Richet P (2009) Kinetics of iron redox reaction in silicate melts: A high temperature Xanes study on an alkali basalt. J Phys Conf Ser 190:012182.

Cochain B, Neuville DR, de Ligny, D., Malki, M., Testemale, D., Pinet, O., Richet, P., 2013. Dynamics of iron-bearing borosilicate melts: effects of melt structure and composition on viscosity, electrical conductivity and kinetics of redox reactions. J Non-Cryst Solids 373-374:18-27.

Cooney, T.F., Sharma, S.K., 1990. Structure of glasses in the systems $\mathrm{Mg}_{2} \mathrm{SiO}_{4}-\mathrm{Fe}_{2} \mathrm{SiO}_{4}, \mathrm{Mn}_{2} \mathrm{SiO}_{4}-\mathrm{Fe}_{2} \mathrm{SiO}_{4}$, $\mathrm{Mg}_{2} \mathrm{SiO}_{4}-\mathrm{CaMgSiO}_{4}$, and $\mathrm{Mn}_{2} \mathrm{SiO}_{4}-\mathrm{CaMnSiO}_{4}$. J Non-Cryst Solids 122, 10-32.

Cooper, R.F., Fanselow, J.B., Poker, D.B., 1996a. The mechanism of oxidation of a basaltic glass: chemical diffusion of network-modifying cations. Geochim Cosmoch Acta 60, 3253-3265.

Cooper, R.F., Fanselow, J.B., Weber, J.K.R., Merkley, D.R., Poker, D.B., 1996b. Dynamics of oxidation of a $\mathrm{Fe}^{2+}$-bearing aluminosilicate (basaltic) melt. Science 274, 1173-1176.

Cottrell E, Kelley KA, Lanzirotti A, Fischer RA (2009) High-precision determination of iron oxidation state in silicate glasses using XANES. Chem Geol 268:167-179.

Cottrell E, Lanzirotti A, Mysen BO, et al (2018) A Mössbauer-based XANES calibration for hydrous basalt glasses reveals radiation-induced oxidation of Fe. Am Mineral 103:489-501.

Dickenson MP, Hess PC (1982) Redox equilibria and the structural role of iron in alumino-silicate melts. Contr Mineral Petrol 78:352-357.

Di Genova D, Kolzenburg S, Wiesmaier S, et al (2017) A compositional tipping point governing the mobilization and eruption style of rhyolitic magma. Nature 552:235-238.

Dingwell DB (1991) Redox viscometry of some Fe-bearing silicate melts. Am Mineral 76:1560-1562.

Dingwell DB, Brearley M, Dickinson JE (1988) Melt densities in the $\mathrm{Na}_{2} \mathrm{O}-\mathrm{FeO}-\mathrm{Fe}_{2} \mathrm{O}_{3}-\mathrm{SiO}_{2}$ system and the partial molar volume of tetrahedrally-coordinated ferric iron in silicate melts. Geochim Cosmoch Acta 52:2467-2475.

Dingwell DB, Virgo D (1988) Viscosities of melts in the $\mathrm{Na}_{2} \mathrm{O}-\mathrm{FeO}-\mathrm{Fe}_{2} \mathrm{O}_{3}-\mathrm{SiO}_{2}$ system and factors controlling relative viscosities of fully polymerized silicate melts. Geochim Cosmoch Acta 52:395-403.

Drewitt JWE, Sanloup C, Bytchkov A, Brassamin S, Hennet L (2013) Structure of $\left(\mathrm{Fe}_{\mathrm{x}} \mathrm{Ca} a_{1-\mathrm{x}} \mathrm{O}\right)_{\mathrm{y}}\left(\mathrm{SiO}_{2}\right)_{1-\mathrm{y}}$ liquids and glasses from high-energy x-ray diffraction: Implications for the structure of natural 
basaltic magmas. Phys. Rev. B - Condens. Matter Mater. Phys. 87(22):1-10.

Fiege A, Ruprecht P, Simon AC, Bell AS, Göttlicher J, Newville M, Lanzirotti T and Moore G (2017). Calibration of $\mathrm{Fe}$ XANES for high-precision determination of $\mathrm{Fe}$ oxidation state in glasses: Comparison of new and existing results obtained at different synchrotron radiation sources. Am Mineral 102(2):369-380.

Fincham CJB, Richardson FD (1954) The behaviour of sulphur in silicate and aluminate melts. P Roy Soc A: Math Phys 223:40-62.

Flood H, Förland, T (1947) The acidic and basic properties of oxides. Acta Chem. Scand, 1, 592-604.

Fox KE, Furukawa T, White WB (1982) Transition metal ions in silicate melts. Part 2. Iron in sodium silicate glasses. Phys Chem Glasses 23:169-178.

Fraser DG (1975) Activities of trace elements in silicate melts. Geochim Cosmoch Acta 39, 1525-1530.

Galoisy L, Calas G, Arrio MA (2001) High-resolution XANES spectra of iron in minerals and glasses: structural information from the pre-edge region. Chem Geol 174:307-319.

Ghiorso MS, Sack RO (1995) Chemical mass transfer in magmatic processes IV. A revised and internally consistent thermodynamic model for the interpolation and extrapolation of liquid-solid equilibria in magmatic systems at elevated temperatures and pressures. Contrib Mineral Petrol 119(2-3):197-212.

Giuli G, Alonso-Mori R, Cicconi MR, et al (2012) Effect of alkalis on the Fe oxidation state and local environment in peralkaline rhyolitic glasses. Am Mineral 97:468-475.

Goldman DS, Gupta PK (1983) Diffusion-controlled redox kinetics in a glassmelt. J Am Ceram Soc 66:188190.

Gonçalves Ferreira P, de Ligny D, Lazzari O, et al (2013) Photoreduction of iron by a synchrotron X-ray beam in low iron content soda-lime silicate glasses. Chem Geol 346:106-112.

Gonnermann HM (2015) Magma Fragmentation. Annu Rev Earth Planet Sci 43:431-458.

Gonnermann HM, Manga M, Fagents SA (2013) Dynamics of magma ascent in the volcanic conduit. In: Gregg TKP, Lopes RMC (eds). Cambridge University Press, pp 55-84.

Iacovino, K., Oppenheimer, C., Scaillet, B. and Kyle, P., 2016. Storage and evolution of mafic and intermediate alkaline magmas beneath Ross Island, Antarctica. Journal of Petrology, 57(1), pp.93118.

Jambon A (1982) Tracer Diffusion In Granitic Melts: Experimental Results For Na, K, Rb, Cs, Ca, Sr, Ba, $\mathrm{Ce}, \mathrm{Eu}$ to $1300^{\circ} \mathrm{C}$ and a Model of Calculation. J. Geophys. Res. 87:10797-10810.

Jayasurika KD, O’Neill HStC, Berry AJ, Campbell SJ (2004) A Mössbauer study of the oxidation state of Fe in silicate melts. Am Mineral 89:1597-1609

Jørgensen CK (1969) Oxidation numbers and oxidation states. Springer-Verlag, Berlin.

Kilinc A, Carmichael ISE, Rivers ML, Sack RO (1983) The Ferric-Ferrous ratio of natural silicate liquids equilibrated in air. Contrib Mineral Petrol 83:136-140.

Kress VC, Carmichael IS (1991) The compressibility of silicate liquids containing $\mathrm{Fe}_{2} \mathrm{O}_{3}$ and the effect of composition, temperature, oxygen fugacity and pressure on their redox states. Contrib Mineral Petrol 108:82-92. 
Kyle, P.R., Moore, J.A. and Thirlwall, M.F., 1992. Petrologic evolution of anorthoclase phonolite lavas at Mount Erebus, Ross Island, Antarctica. Journal of Petrology, 33(4), pp.849-875.

Le Losq C, Berry AJ, Kendrick MA, Neuville DR, O’Neill HStC (2019) Determination of the oxidation state of iron in Mid-Ocean Ridge basalt glasses by Raman spectroscopy. Am Mineral 104:1032-1049.

Le Losq C, Cicconi MR, Neuville DR (2020) Iron in silicate glasses and melts: implications for volcanological processes, in: AGU Monograph. American Geophysical Union.

Le Losq C, Neuville DR (2017) Molecular structure, configurational entropy and viscosity of silicate melts: Link through the Adam and Gibbs theory of viscous flow. J Non-Cryst Solids 463:175-188.

Le Losq C, Neuville DR, Moretti R, Kyle, P.R., Oppenheimer, C., 2015. Rheology of phonolitic magmas the case of the Erebus lava lake. Earth Planet Sc Lett 411, 53-61.

Lierenfeld MB, Zajacz Z, Bachmann O, Ulmer P (2018) Sulfur diffusion in dacitic melt at various oxidation states: Implications for volcanic degassing. Geochim Cosmoch Acta 226:50-68.

Magnien V, Neuville DR, Cormier L, Mysen BO, Briois V, Belin S, Pinet O, Richet P (2004) Kinetics of iron oxidation in silicate melts: a preliminary XANES study. Chem Geol 213:253-263.

Magnien V, Neuville DR, Cormier L, Roux J, Hazemann J-L, de Ligny D, Pascarelli S, Vickridge I, Pinet O, Richet P (2008) Kinetics and mechanisms of iron redox reactions in silicate melts: The effects of temperature and alkali cations. Geochim Cosmoch Acta 72:2157-2168.

Métrich N, Susini J, Foy E, et al (2006) Redox state of iron in peralkaline rhyolitic glass/melt: X-ray absorption micro-spectroscopy experiments at high temperature. Chem Geol 231:350-363.

Moretti R (2005) Polymerisation, basicity, oxidation state and their role in ionic modelling of silicate melts. Ann Geophys-italy 48.

Moretti R (2020) Ionic syntax and equilibrium approach to redox exchanges in melts: basic concepts and the case of iron and sulfur in degassing magmas. In Magma redox Geochemistry, AGU Geophysical Monograph (Moretti R, Neuville DR eds.) (submitted)

Moretti R, Ottonello G (2005) Solubility and speciation of sulfur in silicate melts: The Conjugated ToopSamis-Flood-Grjotheim (CTSFG) model. Geochim Cosmoch Acta 69:801-823.

Moussallam Y, Oppenheimer C, Scaillet B, Gaillard F, Kyle P, Peters N, Hartley M, Berlo K, Donovan A (2014) Tracking the changing oxidation state of Erebus magmas, from mantle to surface, driven by magma ascent and degassing. Earth Planet Sc Lett 393, 200-209.

Moussallam Y, Oppenheimer C, Scaillet B, Kyle P (2013) Experimental phase equilibrium constraints on the phonolite magmatic system of Erebus volcano, Antarctica. J Petrol 54:1285-1307.

Mysen BO, Frantz JD (1992) Raman spectroscopy of silicate melts at magmatic temperatures: $\mathrm{Na}_{2} \mathrm{O}-\mathrm{SiO}_{2}$, $\mathrm{K}_{2} \mathrm{O}-\mathrm{SiO}_{2}$ and $\mathrm{Li}_{2} \mathrm{O}-\mathrm{SiO}_{2}$ binary compositions in the temperature range $25-1475^{\circ} \mathrm{C}$. Chem $\mathrm{Geol} 96$, $321-332$.

Mysen BO, Virgo D, Neumann E-R, Seifert FA (1985) Redox equilibria and the structural states of ferric and ferrous iron in melts in the system $\mathrm{CaO}-\mathrm{MgO}-\mathrm{Al}_{2} \mathrm{O}_{3}-\mathrm{SiO}_{2}-\mathrm{Fe}-\mathrm{O}$ : relationships between redox equilibria, melt structure and liquidus phase equilibria. Am Mineral 70:317-331.

Nesbitt HW, Bancroft GM, Henderson GS, Sawyer R, Secco RA (2015) Direct and indirect evidence for free 
oxygen $\left(\mathrm{O}^{2-}\right)$ in MO-silicate glasses and melts $(\mathrm{M}=\mathrm{Mg}, \mathrm{Ca}, \mathrm{Pb})$. Am Mineral 100:2566-2578.

Neuville DR, Hennet L, Florian P, De Ligny D (2014) In situ High-Temperature Experiments, in: Rev in Mineral Geochem 78:779-800.

O’Neill HStC, Berry AJ, Mallmann G (2018) The oxidation state of iron in Mid-Ocean Ridge basaltic (MORB) glasses: implications for their petrogenesis and oxygen fugacities. Earth Planet Sc Lett 504:152-162

O’Neill HStC, Berry AJ, McCammon CC, et al (2006) An experimental determination of the effect of pressure on the $\mathrm{Fe}^{3+} / \Sigma \mathrm{Fe}$ ratio of an anhydrous silicate melt to 3.0 GPa. Am Mineral 91:404-412.

Oppenheimer C, Lomakina AS, Kyle PR, et al (2009) Pulsatory magma supply to a phonolite lava lake. Earth Planet Sc Lett 284:392-398.

Oppenheimer C, Moretti R, Kyle PR, et al (2011) Mantle to surface degassing of alkalic magmas at Erebus volcano, Antarctica. Earth Planet Sc Lett 306:261-271.

Ottonello G, Moretti R, Marini L, Vetuschi Zuccolini M (2001) Oxidation state of iron in silicate glasses and melts: a thermochemical model. Chem Geol 174:157-179.

Paul A, Douglas RW (1965) Ferrous-ferric equilibrium in binary alkali silicate glasses. Phys Chem Glasses 6:207.

Pauling L (1960) The Nature of the Chemical Bond. Cornell University Press.

Peters, N.J., Oppenheimer, C., Brennan, P., Lok, L.B., Ash, M. and Kyle, P., 2018. Radar altimetry as a robust tool for monitoring the active lava lake at Erebus volcano, Antarctica. Geophysical Research Letters, 45(17), pp.8897-8904.

Ravel B, Newville M (2005) ATHENA, ARTEMIS, HEPHAESTUS: data analysis for X-ray obsorption spectroscopy using IFEFFIT. J Synchrotron Radiat 12:537-541.

Sack RO, Carmichael ISE, Rivers M, Ghiorso MS (1980) Ferric-Ferrous equilibria in natural silicate liquids at 1 bar. Contrib Mineral Petrol 75:369-376.

Sanloup C, Drewitt JWE, Crépisson C, et al (2013) Structure and density of molten fayalite at high pressure. Geochim Cosmochim Acta 118:118-128.

Schreiber HD (1986) Redox processes in glass-forming melts. J Non-Cryst Solids 84:129-141.

Schuessler JA, Botcharnikov RE, Behrens H, et al (2008) Amorphous Materials: Properties, structure, and Durability: Oxidation state of iron in hydrous phono-tephritic melts. Am Mineral 93:1493-1504

Toop GW, Samis CS (1962) Activities of ions in silicate melts. Trans Metall AIME 224:878-887.

Wang Z, Cooney TF, Sharma SK (1995) In situ structural investigation of iron-containing silicate liquids and glasses. Geochim Cosmoch Acta 59:1571-1577.

Wilke M, Farges F, Partzsch GM, Schmidt C, Behrens H (2007a) Speciation of Fe in silicate glasses and melts by in-situ XANES spectroscopy. Am Mineral 92:44-56.

Wilke M, Farges F, Petit P-E, et al (2001) Oxidation state and coordination of Fe in minerals: An Fe KXANES spectroscopic study. Am Mineral 86:714-730.

Wilke M, Partzsch GM, Bernhardt R, Lattard D (2004) Determination of the iron oxidation state in basaltic glasses using XANES at the K-edge. Chem Geol 213:71-87. 
606 Wilke M, Partzsch GM, Welter E, Farges F (2007b) Redox reaction in silicate melts monitored by “static" in-situ Fe K-Edge XANES up to $1180^{\circ} \mathrm{C}$. AIP Conf Proc 882:293-295.

Zhang HL, Cottrell E, Solheid PA, Kelley KA, Hirschmann MM (2018) Determination of $\mathrm{Fe}^{3+} / \Sigma \mathrm{Fe}$ of XANES basaltic glass standards by Mössbauer spectroscopy and its application to the oxidation state of iron in MORB. Chem Geol 479:166-175.

Zhang HL, Hirschmann MM, Cottrell E, Withers AC (2017) Effect of pressure on $\mathrm{Fe}^{3+} / \Sigma \mathrm{Fe}$ ratio in a mafic magma and consequences for magma ocean redox gradients. Geochim Cosmoch Acta 204:83-103. 
608 Table 1: Redox diffusivity $\mathrm{D}_{\text {Redox }}$ calculated from the experiments shown in Figure 2, 3 and 4.

609

1

2

\begin{tabular}{|c|c|c|}
\hline $\mathbf{T}, \mathbf{K}$ & $\begin{array}{c}\mathrm{D}_{\text {Redox }} \\
\log \mathbf{m}^{2} \mathrm{~s}^{-1}\end{array}$ & Error \\
\hline 1400 & -10.9 & $+0.4 /-0.9$ \\
\hline 1423 & -11.2 & $+0.4 /-0.9$ \\
\hline 1603 & -10.5 & $+0.4 /-0.9$ \\
\hline 1603 & -10.3 & $+0.4 /-0.9$ \\
\hline 1673 & -9.9 & $+0.4 /-0.9$ \\
\hline 1693 & -10.1 & $+0.4 /-0.9$ \\
\hline 1773 & -9.3 & $+0.4 /-0.9$ \\
\hline
\end{tabular}

$1 \mathbb{6} 10$

18

1611

2012

22

23

24

25

26

27

28

29

30

31

32

33

34

35

36

37

38

39

40

41

42

43

44

45

46

47

48

49

50

51

52

53

54

55

56

57

58

59

60

61

62

63

64

65 
613 Figure 1: Examples of Fe K-edge XANES spectra of the Erebus phonolitic melt (anhydrous, free from

614 1 crystals) at (A) air $f \mathrm{O}_{2}$ but varying $\mathrm{T}$ (inset: zoom on the pre-edge of the XANES spectra) and (B) constant $\mathrm{T}$ and different $f \mathrm{O}_{2}$ conditions. Signals were stable after a few minutes to tens of minutes (depending on $\mathrm{T}$ ), indicating the attainment of equilibrium conditions at the reported $\mathrm{T}$ and $f \mathrm{O}_{2}$. The higher noise of the $\mathrm{ArH}_{2}$ spectrum results from the higher absorption of X-rays by Argon.

Figure 2: Pre-edge centroid versus integrated intensity CII diagram (A) and centroid versus time (B) during a run where $\mathrm{T}$ was suddenly increased at $\mathrm{t}=142 \mathrm{~s}$ (shown by the black dashed vertical line in $\mathrm{B}$ ) from $1100{ }^{\circ} \mathrm{C}$ to $1420{ }^{\circ} \mathrm{C}$, at constant $f \mathrm{O}_{2}\left(\sim 3.510^{-6}\right)$. The CII diagram shown in (A) was built from the analysis of Fe K-edge XAS spectra of reference minerals, see Supplementary Figure 3. In (B), the black line is a fit to the data using eq. (10), see "Results" section for details. Errors are smaller than symbols and not visible in these plots.

Figure 3: Pre-edge centroid versus integrated intensity CII diagram (A) and centroid versus time (B) during a multi-step run where $\mathrm{T}$ and/or $\mathrm{fO}_{2}$ were changed as indicated for each of five steps of the experiment. Starting conditions for step i are given by step i-1; steps 1 to 5 are indicated in B) along with timings of step changes (vertical dashed lines). In (B), the black dashed lines are fits to the data at each step using eq. (10), see "Results" section for details. Errors are smaller than symbols and not visible in these plots.

Figure 4: Pre-edge centroid versus integrated intensity CII diagram (A) and centroid versus time (B) during a run where $\mathrm{T}$ was suddenly decreased at $\mathrm{t}=0$ from $1550{ }^{\circ} \mathrm{C}$ to $1150{ }^{\circ} \mathrm{C}$, at constant $\mathrm{fO}_{2}$ (air, 0.21 ). In (B), the black dashed line is a fit to the data using eq. (10), see "Results" section for details. Errors are smaller than symbols and not visible in these plots.

Figure 5: Iron oxidation state, expressed as $\mathrm{Fe}^{3+} / \mathrm{Fe}^{\text {TOT }}$, as a function of temperature for the Erebus melt at two different oxygen fugacities: $\operatorname{air}\left(\log f \mathrm{O}_{2}=0.67\right)$ and $\mathrm{N}_{2}\left(\log f \mathrm{O}_{2} \sim 3.510^{-6}\right)$. Symbols are values calculated from the Fe K-edge XANES pre-edge centroid. Dotted and dashed lines are from the models of Kress and Carmichael (1991; KC1991 in legend) and Moretti (2005; M2005 in legend), respectively. The numerical error for each calculation is smaller than the size of symbols.

Figure 6: Redox diffusivity ( $\mathrm{D}_{\text {Redox }}$ ) calculated from eqs. 9-11 and the data presented in figs 2-4 are represented as a function of reciprocal $\mathrm{T}$ as red circles (error bars are represented as small horizontal dashes above/below the symbols). $\mathrm{D}_{\text {Redox }}$ values for an alkali basalt from Cochain et al. (2009) are also reported as grey squares (no error bars are provided from this reference). Lava lake temperatures range between 950 and $1100{ }^{\circ} \mathrm{C}$ (Calkins et al., 2008; Burgisser et al., 2012; Moussallam et al., 2013). Do was calculated from the viscosity of the Erebus phonolite melt using the Eyring equation (Le Losq et al., 2015) ; $\mathrm{D}_{\mathrm{Na}}$ and $\mathrm{D}_{\mathrm{K}}$ are from (Zhang et al., 2010) for silica rich rhyolite dropmelts, $\mathrm{D}_{\mathrm{Ca}}$ and $\mathrm{D}_{\mathrm{S}}$ are also for rhyolites from Jambon (1982) and Baker and Rutherford (1996, ex- 
651 periments involving a mixture of $\mathrm{S}$ species), respectively, and $\mathrm{D}_{\mathrm{Mg}}$ was calculated for the Erebus 652 composition from eq. 23 in Zhang et al. (2010). All D are for low-pressure anhydrous conditions, 353 representative of that of the Erebus lava lake (water content $\sim 0.2 \mathrm{wt} \%$ ). 


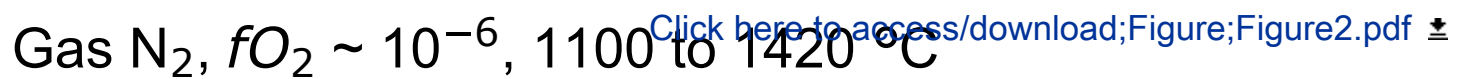
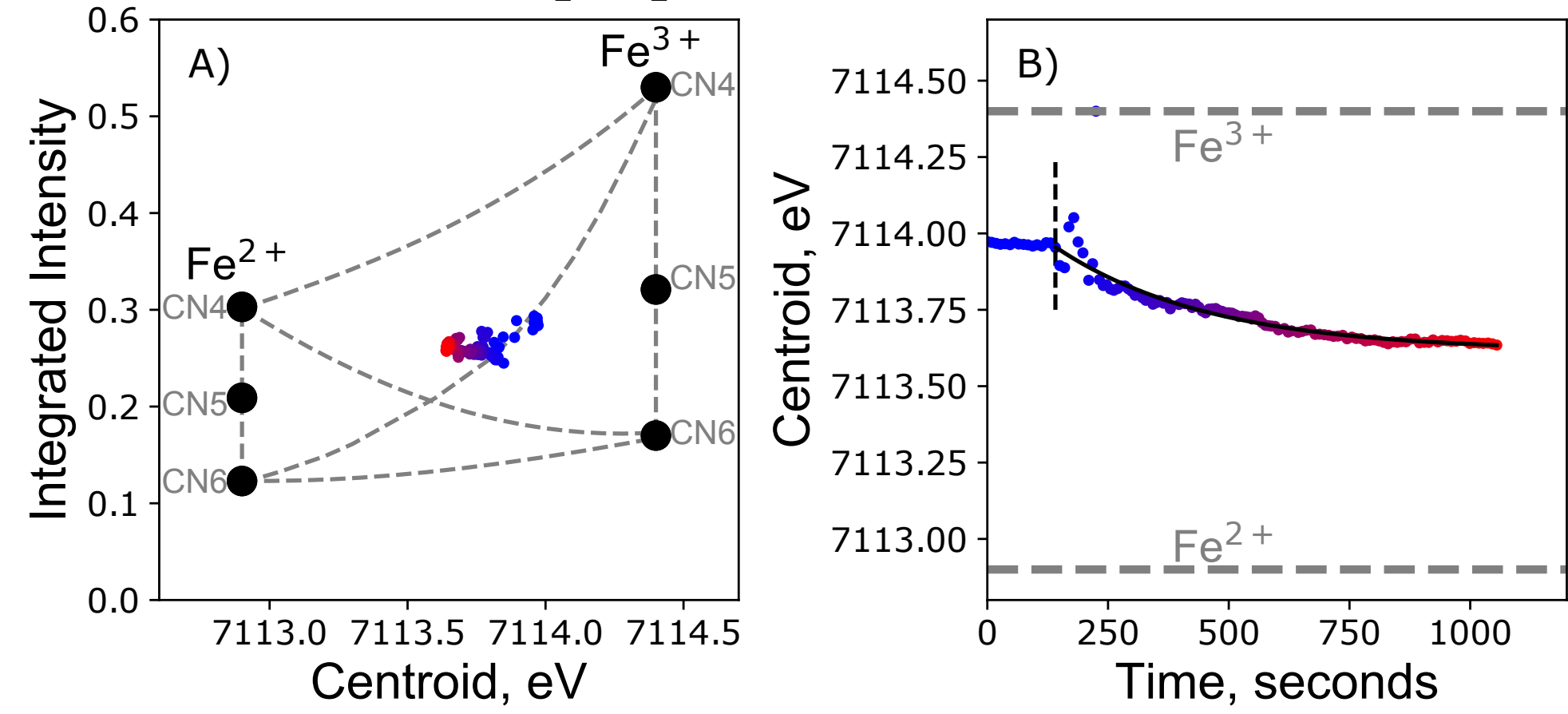


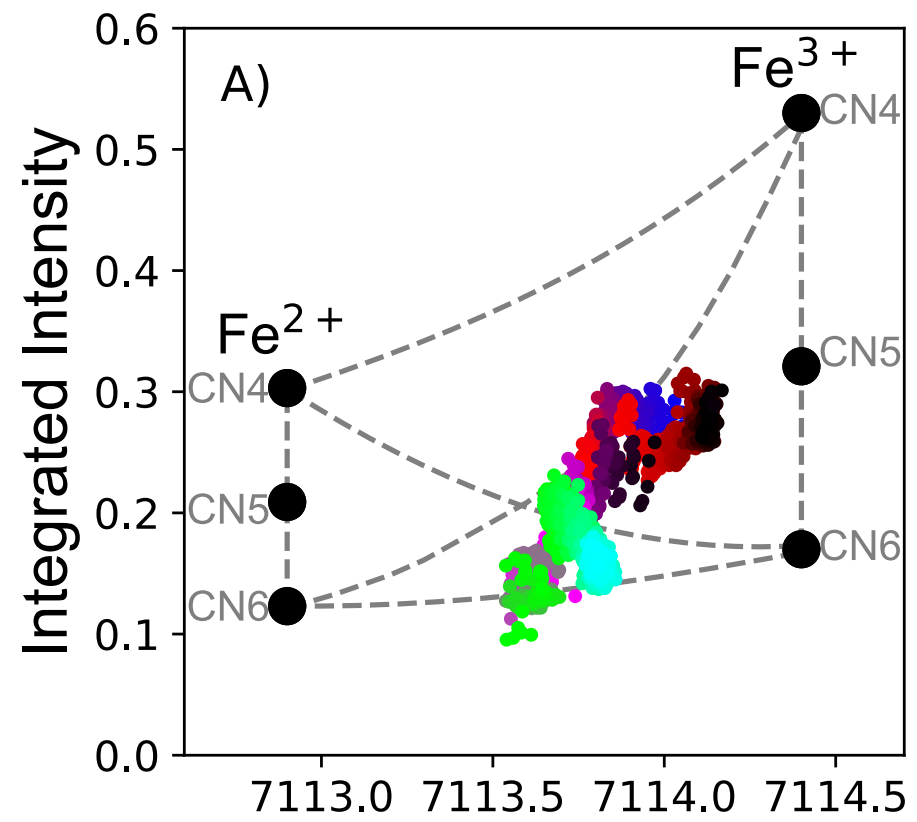

Centroid, eV

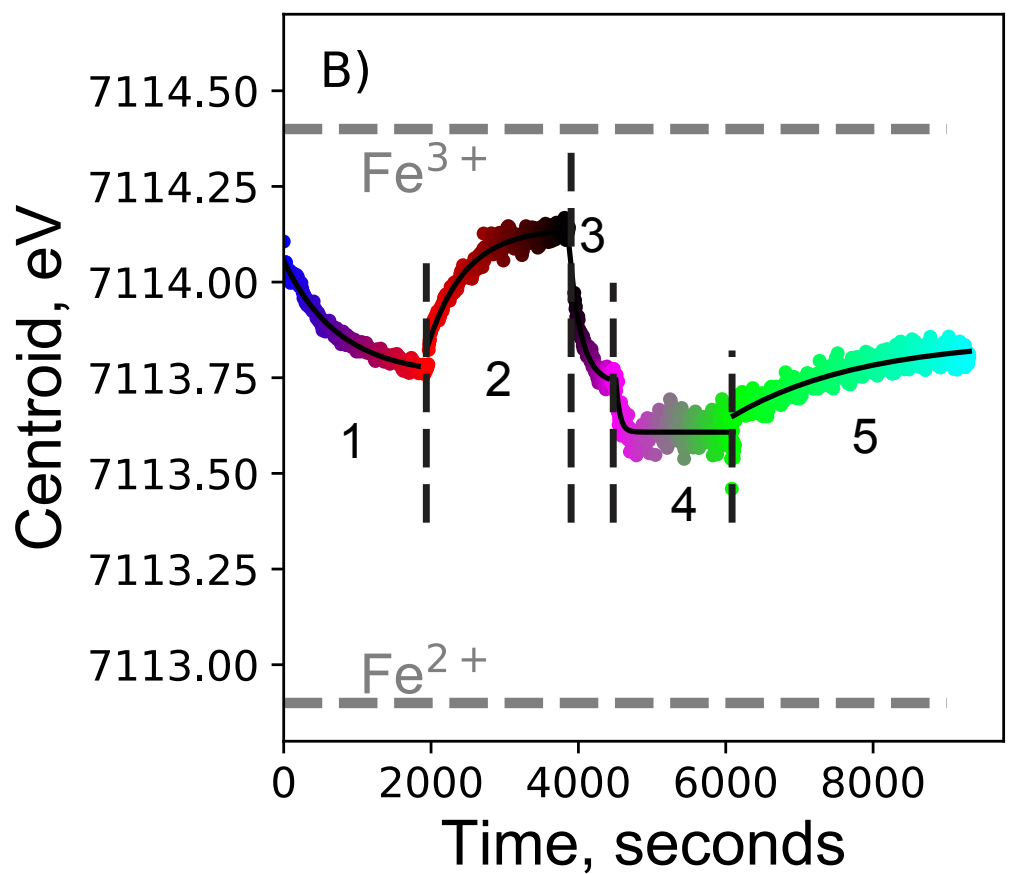

Starting condition $0: \mathrm{O}_{2}$ gas at $1115^{\circ} \mathrm{C}$ Step 1: $\mathrm{N}_{2}$ gas at $1330^{\circ} \mathrm{C}$ Step 2: $\mathrm{O}_{2}$ gas at $1120^{\circ} \mathrm{C}$
Step 3: $\mathrm{N}_{2}$ gas at $1400^{\circ} \mathrm{C}$ Step 4: $\mathrm{N}_{2}$ gas at $1500^{\circ} \mathrm{C}$ Step 5: $\mathrm{N}_{2}$ gas at $1130^{\circ} \mathrm{C}$ 


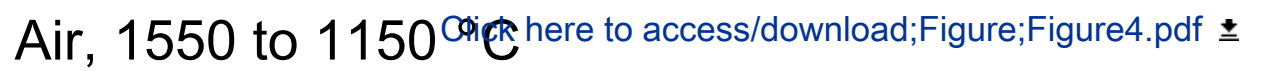
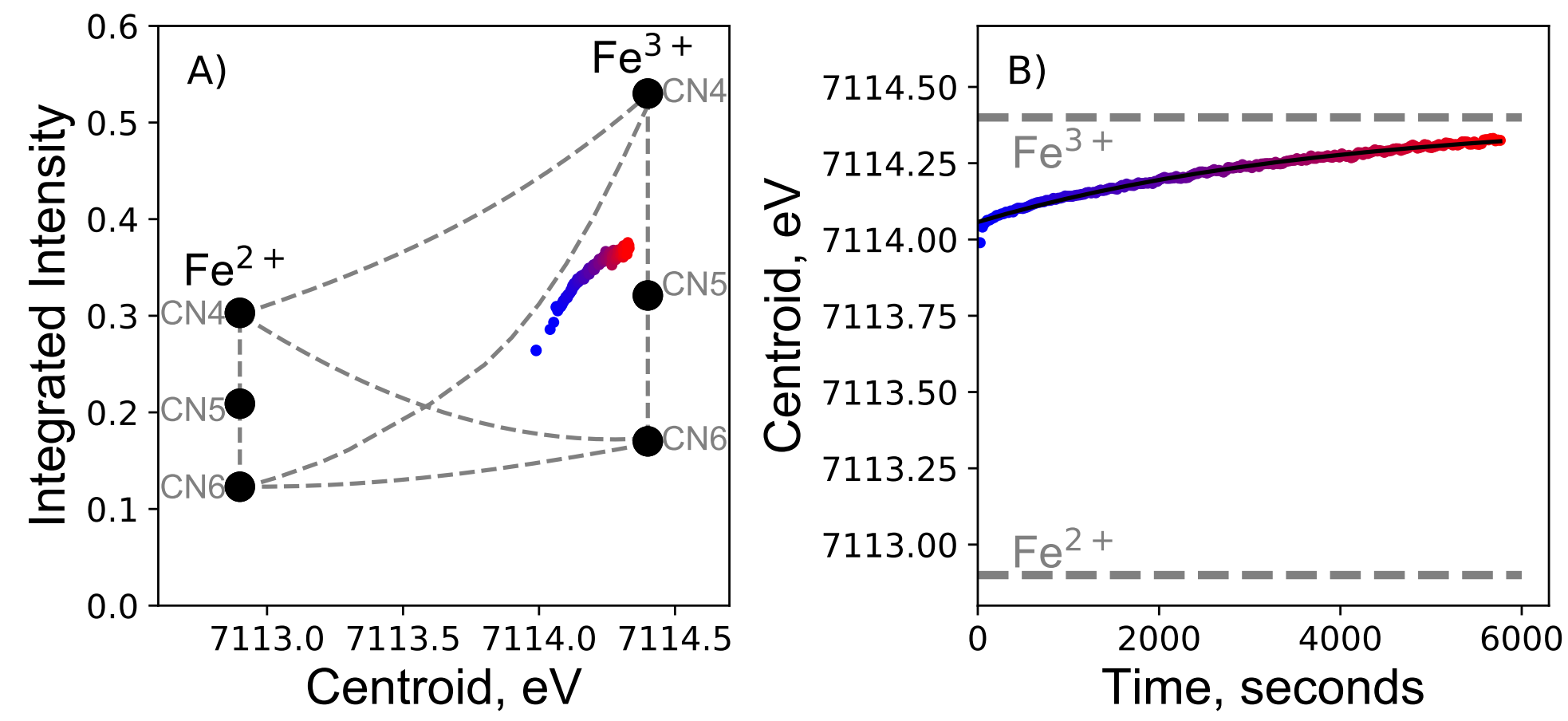
Figure 5

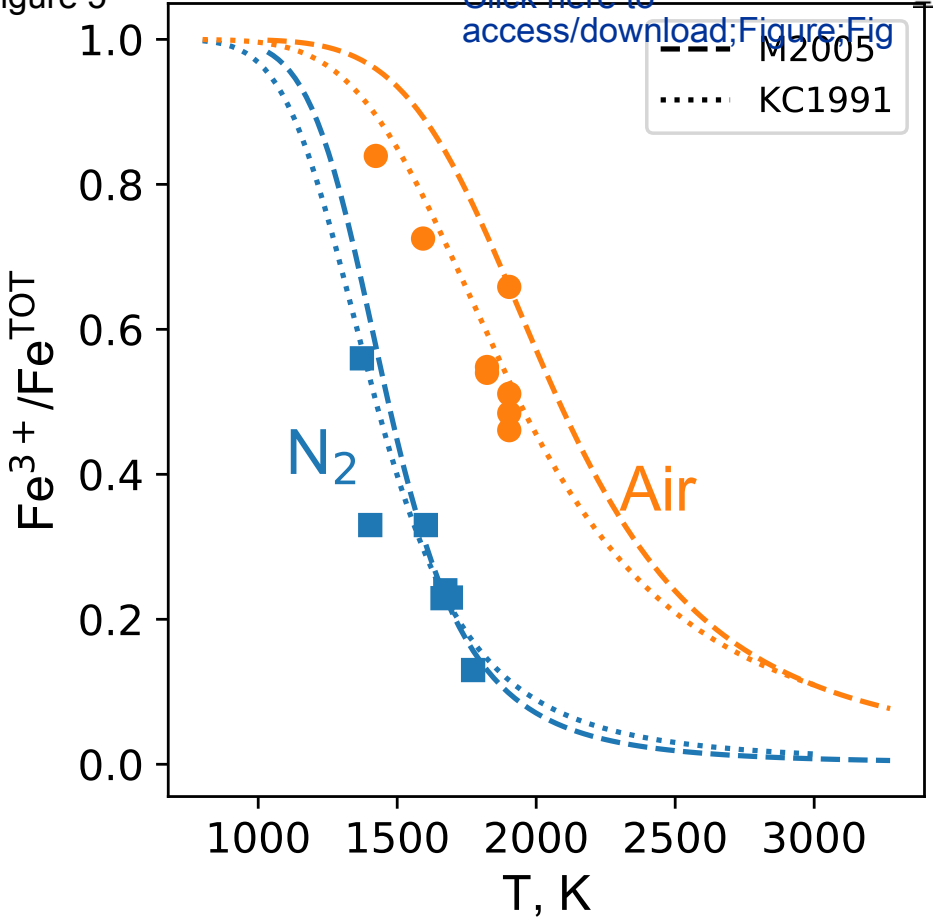


Click here to

access/download;Figure;Figure6.pdf

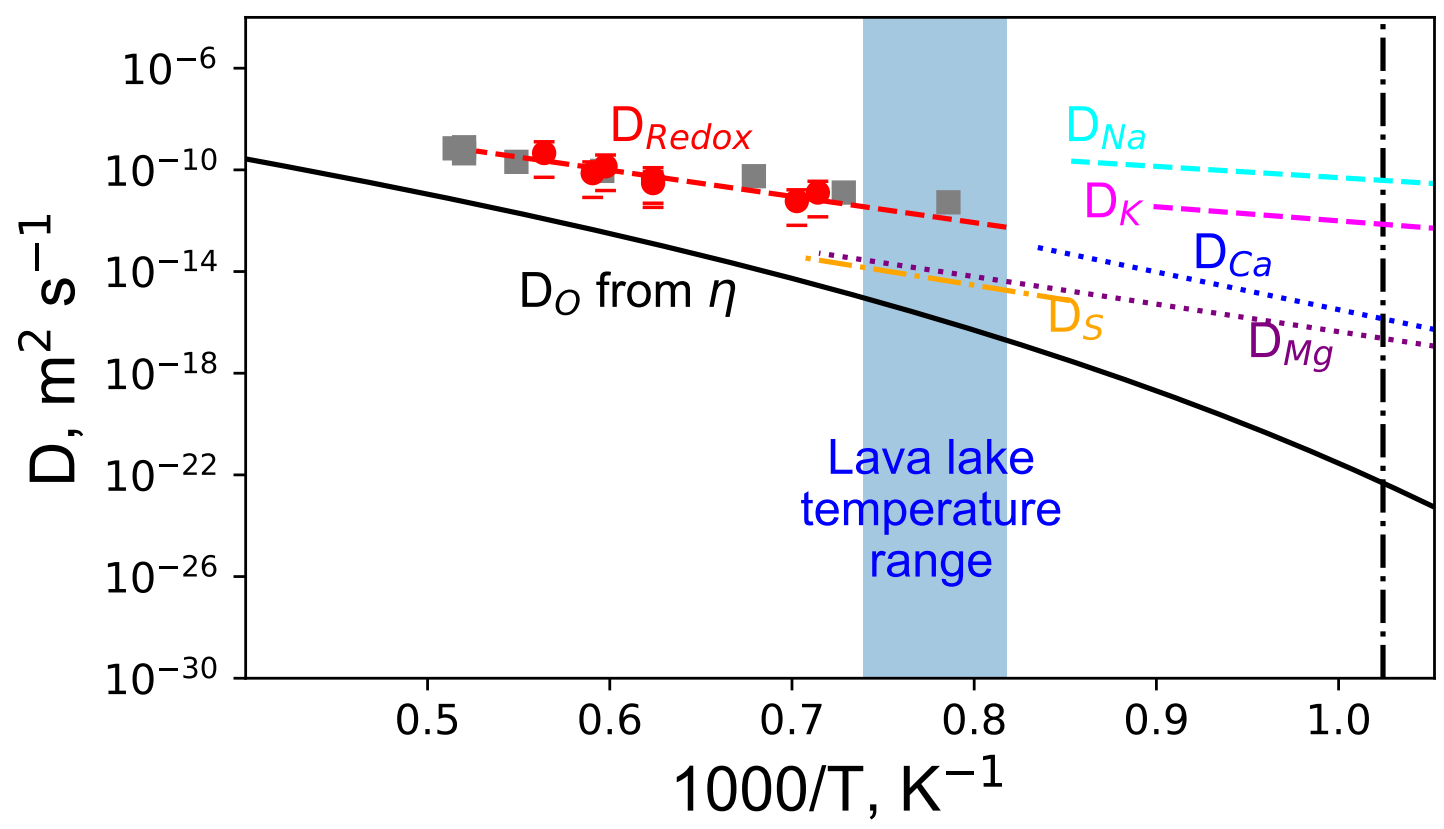




\section{Supplementary Materials}

\section{In situ XANES study of the influence of varying temperature and oxygen fugacity on iron oxidation state and coordination in a phonolitic melt}

Charles Le Losq ${ }^{1,2^{*}}$, Roberto Moretti ${ }^{1,3}$, Clive Oppenheimer ${ }^{4}$, François Baudelet ${ }^{5}$, Daniel R. Neuville ${ }^{1}$

Contributions to Mineralogy and Petrology

\footnotetext{
${ }^{1}$ Université de Paris, Institut de Physique du Globe de Paris, UMR 7154 CNRS, 75005 Paris, France

${ }^{2}$ Research School of Earth Sciences, The Australian National University, Building 142, Mills Road, Acton, ACT 2601, Australia.

${ }^{3}$ Observatoire Volcanologique et Sismologique de Guadeloupe, Institut de Physique du Globe de Paris, 97113 Gourbeyre, France

${ }^{4}$ Department of Geography, University of Cambridge, Downing Place, Cambridge, CB2 3EN, United Kingdom.

${ }^{5}$ SOLEIL Synchrotron

*Corresponding author: lelosq@ipgp.fr
} 


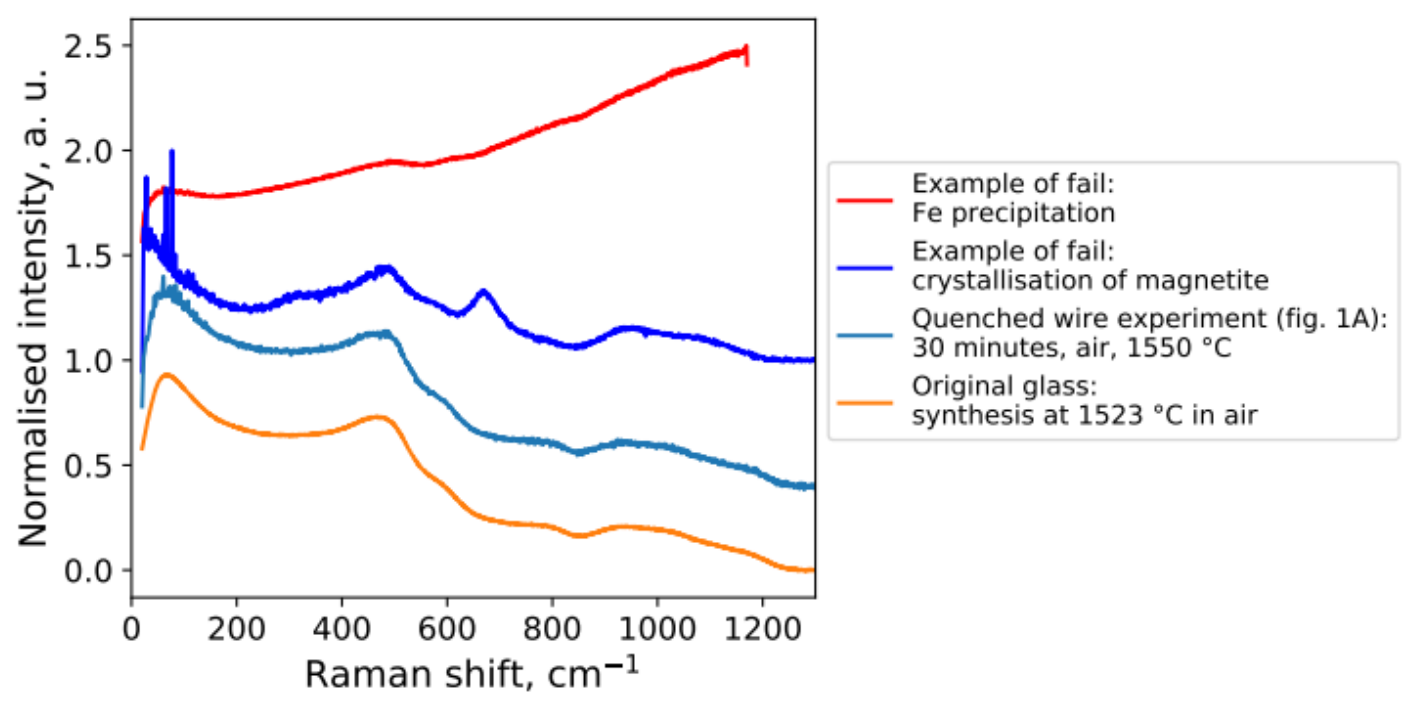

Supplementary Figure 1: Raman spectra of the original glass, of a glass after an experiment in air (30 minutes at $1550{ }^{\circ} \mathrm{C}$ ), and of two dynamic runs were iron loss or crystallisation were detected during the runs (via the XAS signals that appears every $\sim 1-2$ seconds on the monitoring screen on the beamline). The lack of difference between the initial glass (synthesised in air, at $1523{ }^{\circ} \mathrm{C}$ ) and that obtained after running 30 minutes in air at $1550{ }^{\circ} \mathrm{C}$ indicate that the chemistry of the melt did not change, within the sensitivity of Raman spectroscopy to glass chemistry ( $\sim$ mol $\%$, e.g. see Le Losq et al. 2019). 

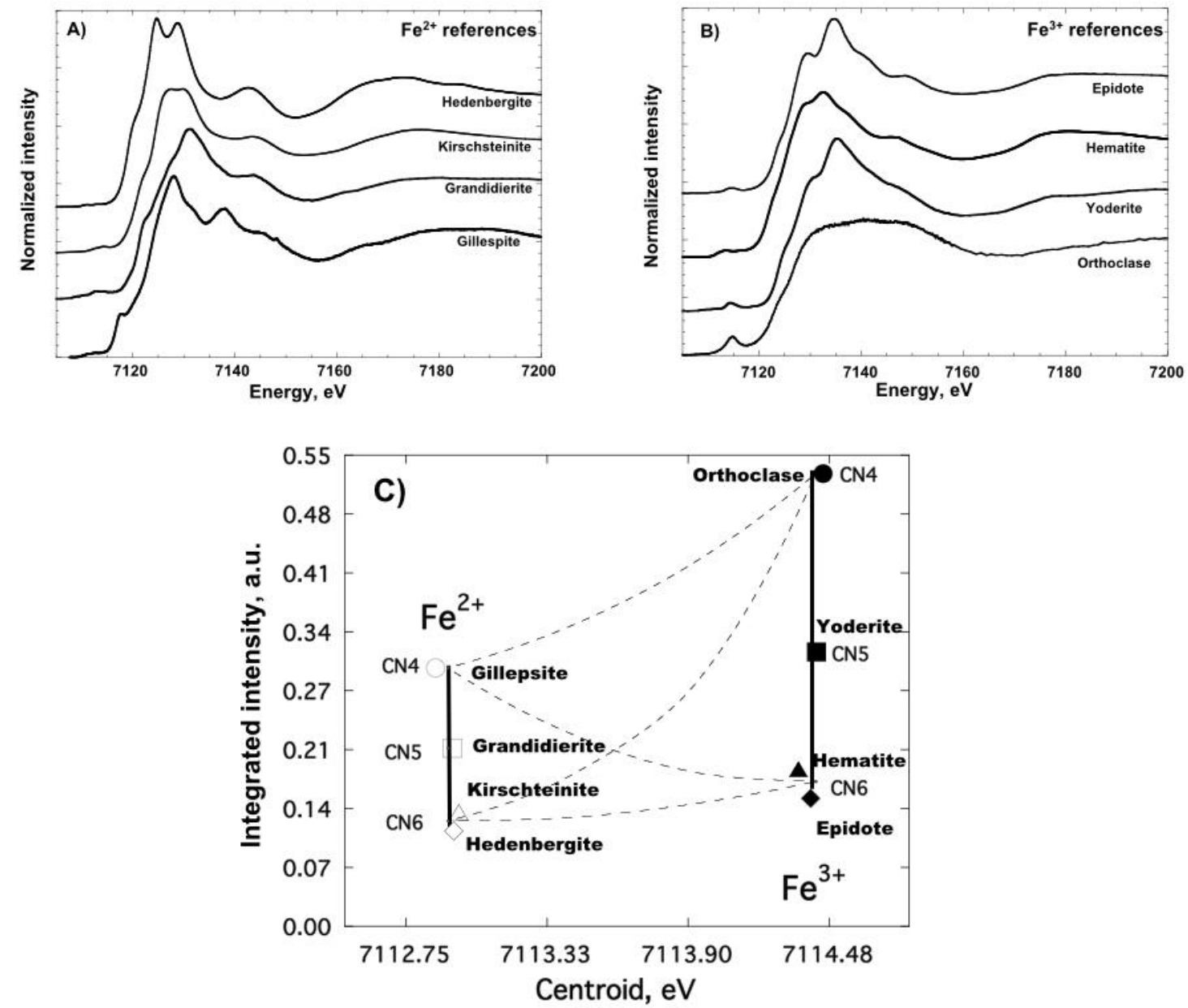

Supplementary Figure 2: A) and B) Fe K-edge XANES spectra of $\mathrm{Fe}^{2+}$ and $\mathrm{Fe}^{3+}$ reference minerals, respectively. C) Pre-edge centroid versus integrated intensity diagram, determined using spectra reported above and the data treatment used in this study (see experimental methods). Data from Cochain (2009). 

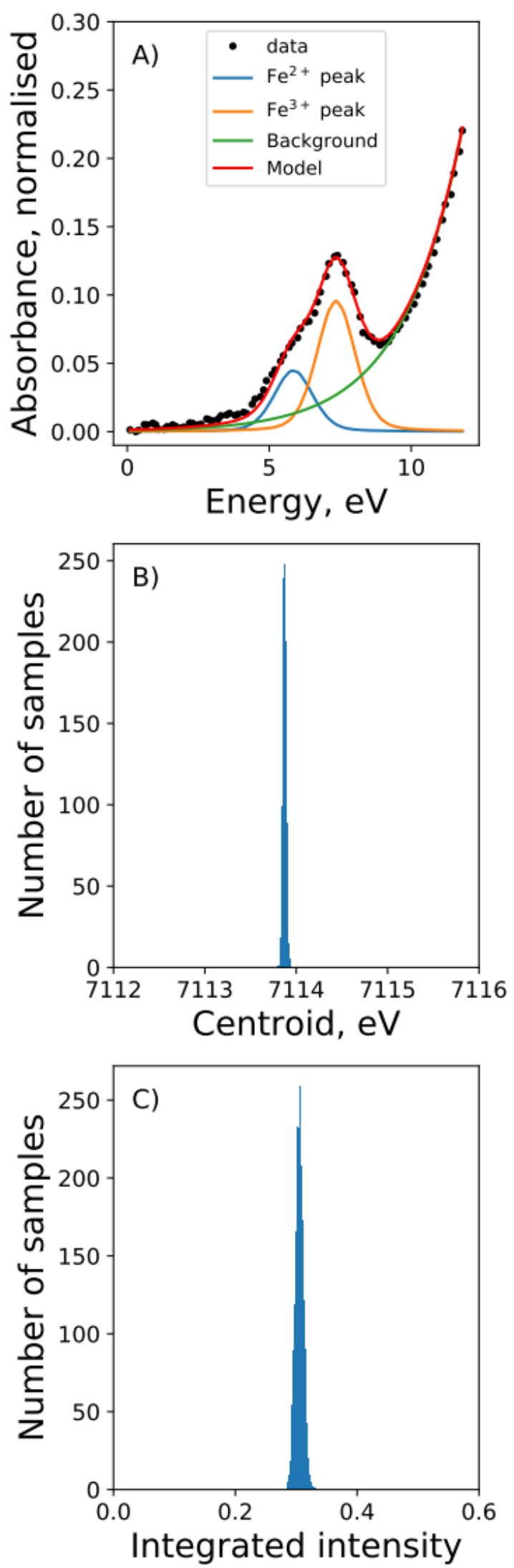

Supplementary Figure 3: A) Example of a fit of the pre-edge. B) and C) posterior probability distributions for the centroid and integrated intensity calculated from 1000 models sampled on the posterior probability distribution of the problem (PyMC3 library, NUTS algorithm sampling 1000 models after 5000 tuning steps). 


\section{Please read the important information on page 4 before you begin}

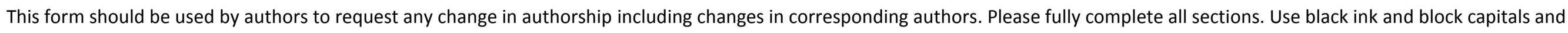
provide each author's full name with the given name first followed by the family name.

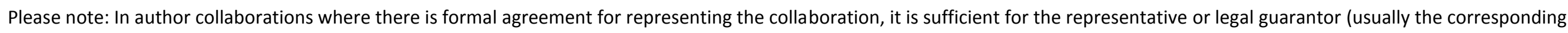
author) to complete and sign the Authorship Change Form on behalf of all authors.

\section{Section 1: Please provide the current title of manuscript}

(For journals: Please provide the manuscript ID, title and/or DOI if available.)

(For books: Please provide the title, ISBN and/or DOI if available.)

\begin{tabular}{|l|}
\hline Manuscript ID no. in case of unpublished manuscript: $\triangle$ CTMP-D-20-00018R1 \\
\hline DOI in case of published manuscript: \\
\hline ISBN (for books): \\
\hline
\end{tabular}

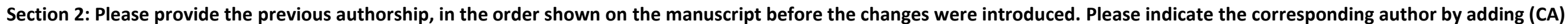
behind the name.

\begin{tabular}{|c|c|c|c|}
\hline & First name(s) & Family name & ORCID or SCOPUS id, if available \\
\hline $1^{\text {st }}$ author & Charles & LE LOSQ (CA) & \\
\hline $2^{\text {nd }}$ author & Roberto & MORETTI & \\
\hline $3^{\text {rd }}$ author & Clive & OPPENHEIMER & \\
\hline $4^{\text {th }}$ author & Daniel & NEUVILLE & \\
\hline $5^{\text {th }}$ author & & & \\
\hline $6^{\text {th }}$ author & & & \\
\hline $7^{\text {th }}$ author & & & \\
\hline
\end{tabular}

Please use an additional sheet if there are more than 7 authors.

SPRINGER NATURE springer Nature is one of the world's leading global research, educational and professional publishers, created in May 2015 through the combination of Nature Publishing Group, Palgrave Macmillan, Macmillan Education and Springer Science+Business Media. 


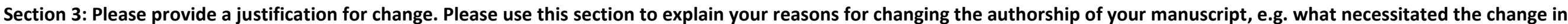

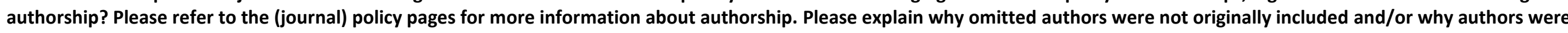
removed on the submitted manuscript.

\section{Dear editorial team, the reasons of the addition of François BAUDELET are explained in the cover letter..}

François was the beamline manager at SOLEIL during the experiments. We originally thanked him in the Acknowledgements. Following a recent contact at SOLEIL early March, François took a look at the manuscript and helped us revise it, bringing some important insights and modifications. Considering his help during the experiments and the new comments on the manuscript, we invited him to join the authorboard in this revised verison.

This is why his name has been added to the authorboard.

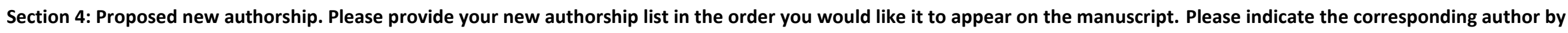
adding (CA) behind the name. If the corresponding author has changed, please indicate the reason under section 3.

\begin{tabular}{|c|c|c|}
\hline & First name(s) & $\begin{array}{l}\text { Family name (this name will appear in full on the final publication and will be searchable in various abstract and indexing } \\
\text { databases) }\end{array}$ \\
\hline $1^{\text {st }}$ author & Charles & LE LOSQ (CA) \\
\hline $2^{\text {nd }}$ author & Roberto & MORETTI \\
\hline $3^{\text {rd }}$ author & Clive & OPPENHEIMER \\
\hline $4^{\text {th }}$ author & François & BAUDELET \\
\hline $5^{\text {th }}$ author & Daniel & NEUVILLE \\
\hline \multicolumn{3}{|l|}{$6^{\text {th }}$ author } \\
\hline $7^{\text {th }}$ author & & \\
\hline
\end{tabular}

Please use an additional sheet if there are more than 7 authors.

SPRINGER NATURE springer Nature is one of the world's leading global research, educational and professional publishers, created in May 2015 through the combination of Nature Publishing Group, Palgrave Macmillan, Macmillan Education and Springer Science+Business Media. 
SSS $\underset{\text { Stafleu }}{\text { Bohn }}$ palgrave

$\triangle$ Adis $2 \mathbb{~}$ van Loghum macmillan

\section{Change of authorship request form (pre-acceptance)}

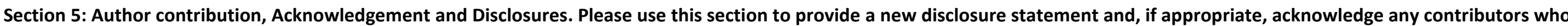

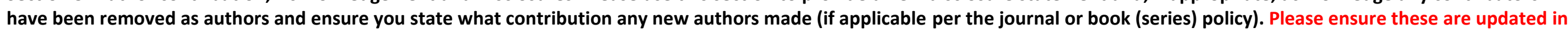
your manuscript - after approval of the change(s) - as our production department will not transfer the information in this form to your manuscript.
New acknowledgements:
We acknowledge SOLEIL (Gif sur Yvette, France) for provision of synchrotron radiation facilities (proposal 20101038). CLL acknowledges support received from the Australian Research Council Laureate Fellowship (FL130100066) of Hugh St.C. O'Neill as well as from the Chaire d'Excellence of the University of Paris during data processing and manuscript preparation. $\mathrm{CO}$ acknowledges support from the Natural Environment Research Council (grant NE/N009312/1)

New Disclosures (financial and non-financial interests, funding):

Not applicable

New Author Contributions statement (if applicable per the journal policy):

CO collected the samples for analysis. CLL, RM, CO and DN designed the study. CLL, RM, FB and DN performed the XANES experiments. CLL processed the data and drafted the manuscript. All authors contributed to the final version of the manuscript.

State 'Not applicable' if there are no new authors.

SPRINGER NATURE springer Nature is one of the world’s leading global research, educational and professional publishers, created in May 2015 through the combination of Nature Publishing Group, Palgrave Macmillan, Macmillan Education and Springer Science+Business Media. 


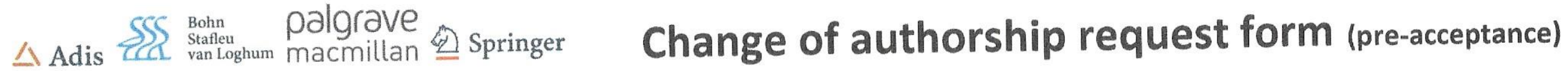

Section 6: Declaration of agreement. All authors, unchanged, new and removed must sign this declaration.

Section 6: Declaration of age

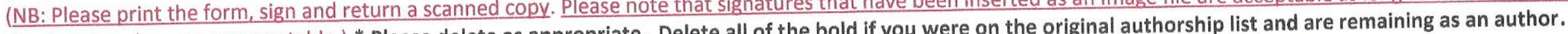

the signature box are unacceptable.) * Please delete as appropriate. Delete all of the bold if you were on the original authorship ilst and are

\begin{tabular}{|c|c|c|c|c|c|c|}
\hline & First name & Family name & & Signature & Affiliated institute & Date \\
\hline $\begin{array}{l}1^{\text {st }} \\
\text { author }\end{array}$ & Charles & LE LOSQ (CA) & $\begin{array}{l}\text { I agree to the proposed new authorship } \\
\text { shown in section } 4 \text { /and the } \\
\text { addition/removal* of my name to the } \\
\text { authorship list. }\end{array}$ & & IPGP - University of Paris & $15 / 05 / 2020$ \\
\hline $\begin{array}{l}2^{\text {nd }} \\
\text { author }\end{array}$ & Roberto & MORETTI & $\begin{array}{l}\text { I agree to the proposed new authorship } \\
\text { shown in section } 4 \text { /and the } \\
\text { addition/removal* of my name to the } \\
\text { authorship list. }\end{array}$ & & IPGP - University of Paris & $15 / 05 / 2020$ \\
\hline $\begin{array}{l}3^{\text {rd }} \\
\text { author }\end{array}$ & Clive & OPPENHEIMER & $\begin{array}{l}\text { I agree to the proposed new authorship } \\
\text { shown in section } 4 \text { /and the } \\
\text { addition/removal* of my name to the } \\
\text { authorship list. }\end{array}$ & & University of Cambridge & 17 May 2020 \\
\hline $\begin{array}{l}4^{\text {th }} \\
\text { authors }\end{array}$ & François & BAUDELET & $\begin{array}{l}\text { I agree to the proposed new authorship } \\
\text { shown in section } 4 \text { /and the } \\
\text { addition/removal* of my name to the } \\
\text { authorship list. }\end{array}$ & & SOLEIL Synchrotron & 18/05/2020 \\
\hline $\begin{array}{l}5^{\text {th }} \\
\text { author }\end{array}$ & Daniel & NEUVILLE & $\begin{array}{l}\text { I agree to the proposed new authorship } \\
\text { shown in section } 4 \text { /and the } \\
\text { addition/removal* of my name to the } \\
\text { authorship list. }\end{array}$ & & IPGP - University of Paris & $15 / 05 / 2020$ \\
\hline $\begin{array}{l}6^{\text {th }} \\
\text { author }\end{array}$ & & & $\begin{array}{l}\text { I agree to the proposed new authorship } \\
\text { shown in section } 4 \text { /and the } \\
\text { addition/removal* of my name to the } \\
\text { authorship list. }\end{array}$ & & & \\
\hline $\begin{array}{l}7^{\text {th }} \\
\text { author }\end{array}$ & & & $\begin{array}{l}\text { I agree to the proposed new authorship } \\
\text { shown in section } 4 \text { /and the } \\
\text { addition/removal* of my name to the } \\
\text { authorship list. }\end{array}$ & & & $=$ \\
\hline
\end{tabular}

Please use an additional sheet if there are more than 7 authors.

SPRINGER NATURE Springer Nature is one of the world's leading global research, educational and professional publishers, created in May 2015

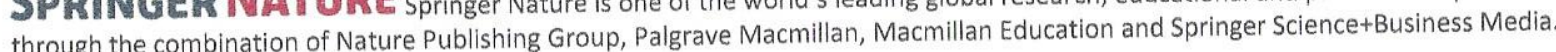

$\ldots$ 


\section{Important information. Please read.}

- Please return this form, fully completed, to Springer Nature. We will consider the information you have provided to decide whether to approve the proposed change in authorship. We may choose to contact your institution for more information or undertake a further investigation, if appropriate, before making a final decision.

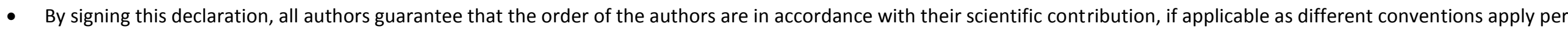
discipline, and that only authors have been added who made a meaningful contribution to the work.

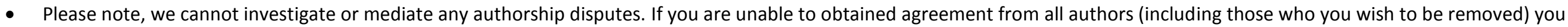
must refer the matter to your institution(s) for investigation. Please inform us if you need to do this.

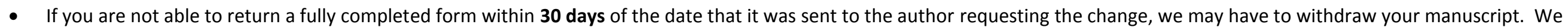
cannot publish manuscripts where authorship has not been agreed by all authors (including those who have been removed).

- Incomplete forms will be rejected. 